\title{
Density Functional Theory Basis Set Convergence of Sulfuric Acid-Containing Molecular Clusters
}

\author{
Nanna Myllys ${ }^{\mathrm{a}}$, Jonas Elm*a, Theo Kurtén ${ }^{\mathrm{b}}$ \\ ${ }^{a}$ Department of Physics, University of Helsinki, Finland \\ ${ }^{b}$ Department of Chemistry, University of Helsinki, Finland \\ * Corresponding author. E-mail address: jonas.elm@helsinki.fi
}

\begin{abstract}
We investigate the basis set convergence of three density functionals (M062X, PW91, and $\omega$ B97X-D) with respect to the binding energy, thermal contribution to the Gibbs free energy, and optimized geometry. We apply correlation consistent, Pople-type, and polarization consistent basis sets with different amount of diffuse and polarization functions. Our test set contains six molecular cluster formation reactions which represent key noncovalent interactions in the atmosphere. In most cases partially augmented basis sets yield as accurate results as the fully augmented basis sets, with significant gain in computational efficiency. Relatively small basis sets are found to be sufficient to optimize geometries and to calculate thermal contributions to the Gibbs free energy. For binding energies, slightly bigger basis sets are needed to reach the complete basis set limit. The PW91 functional with the $6-311++\mathrm{G}(3 \mathrm{df}, 3 \mathrm{pd})$ basis set gives a mean absolute error of $0.9 \mathrm{kcal} / \mathrm{mol}$ in the binding energy, indicating that it has not reached the complete basis set limit. We estimate the effect of anharmonicity and derive scale factors to correct for it. When the lowest vibrational frequencies are treated separately, the errors arising from the anharmonicity of the remaining frequencies are small regardless of system size. We treated the low frequencies as free rotors and calculate thermal contributions to the Gibbs free energy using the quasi-harmonic approximation. We identify an error of a few percent of the total harmonic thermal contributions, which is larger than the error arising from vibrational anharmonicity.

Keywords: Basis Set Convergence, Density Functional Theory, Molecular Clusters
\end{abstract}




\section{Introduction}

Noncovalent interactions play an important role in atmospheric newparticle formation [1]. They control the first steps of clustering, the orientation of molecules on aerosol particles, cluster hydration, and the properties of particle surfaces.[2, 3, 4, 1] Molecules collide with each others in the atmosphere, and may form stable complexes via hydrogen-bond formation or acid-to-base proton transfer. The formation of new particles is not fully understood, but according to current knowledge is believed to involve sulfuric acid coupled with a stabilizing component such as ammonia, amines, or organic compounds $[5,6,7,8]$. Computational chemistry is a useful tool to increase the understanding of the first steps in new-particle formation, as the precise composition and properties of small clusters are difficult to measure experimentally. Computational methods are used to calculate Gibbs free energies of formation which can be used to estimate clusters stabilities. High level quantum chemical calculations give valuable information about atmospheric molecular clusters, but are limited to small clusters due to their computational cost. Presently, density functional theory is the most widely used computational method and density functionals, which can describe noncovalent interactions more accurately, have become increasingly popular $[9,10,11,12,13,14]$. This is because wave function methods such as $\operatorname{CCSD}(\mathrm{T})$ are much more expensive, and also tend to require large basis sets to yield accurate results, while most density functionals are able to perform well with smaller basis sets $[15,16]$. However, our earlier studies have shown that the binding energy is the largest source of error when using only density functional theory to calculate Gibbs free energy of formation of atmospheric relevant clusters [17, 18]. A common way to circumvent this issue is to employ a multi-step quantum chemical approach to calculate Gibbs free energies[19], where the DFT binding energies are corrected using high-level coupled cluster methods calculated on top of the DFT geometries. However, the single point energy is dependent on the optimized structure and the Gibbs free energy also depends on the thermal contribution. Using density functional theory methods, we focus on the basis set convergence of the DFT binding energy, the thermal contribution to the Gibbs free energy, and the effects that small perturbations in the molecular structures have on the subsequent higher level calculation of the binding energy. To calculate thermochemical properties, the most commonly used approach is the Rigid Rotor-Harmonic Oscillator (RRHO) approximation. However, the lowest vi- 
brational frequencies are often inaccurate in the harmonic approximation, so we recompute the partition functions using the free-rotor model for low-lying frequencies and RRHO approach for other modes[20]. This so-called quasiharmonic approximation should give more reliable thermochemical parameters as it corrects the unphysical vibrational entropy for the lowest vibrational frequencies in the RRHO approach. In addition to correcting the RRHO approximation, we derive scale factors between harmonic and anharmonic frequencies. Several approaches have been used to account for vibrational anharmonicity, for example, vibrational self-consistent field (VSCF)[21] method for organic molecules[22, 23], the second order perturbation corrected VSCF theory (VSCF-PT2)[24] for hydrogen bonded systems[25], and vibrational second order perturbation theory (VPT2)[26] for large water clusters[27, 28]. In this study, we quantity the effect of vibrational anharmonicity using the VPT2 method. The main objectives in the present study are to test the accuracy of different basis sets in terms of geometry optimization, the thermal contribution to the Gibbs free energy, the binding energy and to discuss ways of improving the RRHO approximation. We seek out to identify how small a basis set can be applied, while still yielding accurate results in order to do accurate calculations on larger molecular clusters than previously attainable.

\section{Methods}

All density functional theory calculations were run using Gaussian09 [29]. To study how different basis sets affect the geometry optimization, we calculate single point energies with a domain-based local pair natural orbital coupled cluster method, DLPNO-CCSD(T) [30, 31], with the def2-QZVPP basis set [32] using ORCA [33]. The cluster binding energies (Eq. 1) and the thermal contribution to the Gibbs free binding energies (Eq. 2) are calculated as follows:

$$
\begin{gathered}
\Delta E_{\text {binding }}=E_{\text {cluster }}-\sum_{i} E_{\text {monomer }, i} \\
\Delta G_{\text {Therm }}=G_{\text {Therm,cluster }}-\sum_{i} G_{\text {Therm,monomer }, i}
\end{gathered}
$$

The cluster Gibbs free binding energies (Eq. 3) are calculated as a sum of binding energy and thermal contribution to the Gibbs free energy. The thermal contribution also contains the vibrational zero point energy.

$$
\Delta G_{\text {binding }}=\Delta E_{\text {binding }}+\Delta G_{\text {Therm }}
$$


We investigate the following six molecular cluster formation reactions:

$$
\begin{aligned}
& \mathrm{H}_{2} \mathrm{SO}_{4}+\mathrm{NH}_{3} \rightleftharpoons\left(\mathrm{H}_{2} \mathrm{SO}_{4}\right)\left(\mathrm{NH}_{3}\right) \\
& \mathrm{H}_{2} \mathrm{SO}_{4}+\left(\mathrm{CH}_{3}\right)_{2} \mathrm{NH} \rightleftharpoons\left(\mathrm{H}_{2} \mathrm{SO}_{4}\right)\left(\left(\mathrm{CH}_{3}\right)_{2} \mathrm{NH}\right) \\
& \mathrm{H}_{2} \mathrm{SO}_{4}+\mathrm{HCOOH} \rightleftharpoons\left(\mathrm{H}_{2} \mathrm{SO}_{4}\right)(\mathrm{HCOOH}) \\
& \mathrm{H}_{2} \mathrm{SO}_{4}+\mathrm{H}_{2} \mathrm{O} \rightleftharpoons\left(\mathrm{H}_{2} \mathrm{SO}_{4}\right)\left(\mathrm{H}_{2} \mathrm{O}\right) \\
& \mathrm{H}_{2} \mathrm{SO}_{4}+\mathrm{H}_{2} \mathrm{O}+\mathrm{H}_{2} \mathrm{O} \rightleftharpoons\left(\mathrm{H}_{2} \mathrm{SO}_{4}\right)\left(\mathrm{H}_{2} \mathrm{O}\right)_{2} \\
& \mathrm{H}_{2} \mathrm{SO}_{4}+\mathrm{H}_{2} \mathrm{SO}_{4} \rightleftharpoons\left(\mathrm{H}_{2} \mathrm{SO}_{4}\right)_{2}
\end{aligned}
$$

The studied reactions represent some of the most important noncovalent interactions in molecular cluster formation in the atmosphere. Reaction R1 represents hydrogen-bond formation between sulfuric acid and an inorganic base, R2 proton transfer from sulfuric acid to a strong organic base, R3 the interaction of sulfuric acid with organic acid, R4 and R5 sulfuric acid hydration, and $\mathrm{R} 6$ the interaction between two sulfuric acids.

We employed the correlation consistent polarized valence basis sets (cc$\mathrm{pV} x \mathrm{Z}, x=2-6)[34,35]$ with added diffuse functions (may, jun, jul, and augcc-pVxZ, $x=2-5)$ [36, 37], double and triple-zeta Pople-type basis sets[38, 39] with different amounts of polarization and diffuse functions [40], and polarization consistent basis sets (pc- $n, n=1-4)[41,42]$ with diffuse functions (aug-pc- $n, n=1-2$ ) [43].

To test basis set convergence, we have chosen one GGA (PW91)[44], one range-separated hybrid-GGA ( $\omega$ B97X-D) [45], and one hybrid-meta-GGA (M06-2X) [46]. The PW91 functional has previously been used extensively for studying atmospheric cluster formation. In recent benchmarks the M06-2X and $\omega$ B97X-D have shown good performance for calculating intermolecular interactions [47] and polarizabilities [48]. Furthermore, these three functionals have been shown to yield reliable results for the electronic energies, thermal contributions, and structures of atmospheric clusters [49, 50, 51].

In the correlation consistent basis set family, the fully augmented basis set, defined "aug", denotes that for every atom one diffuse basis function is added for every angular momentum value of the basis functions present on that atom. Partially augmented basis sets are obtained by removing diffuse subshells on atoms. The jul basis set deletes diffuse functions for hydrogen, but heavier atoms are fully augmented. The jun basis set also removes the highest angular momentum diffuse function for heavier atoms, and the may basis set removes the two highest angular momentum diffuse 
Table 1: Diffuse functions on hydrogen and heavier atoms for double and triple-zeta correlation consistent aug, jul, jun, and may, and Pople-type ++ and + , basis sets.

\begin{tabular}{l|cc|cc}
\hline & $\mathrm{H}$ & $\begin{array}{c}\text { Double-zeta } \\
\mathrm{C}, \mathrm{N}, \mathrm{O}, \mathrm{S}\end{array}$ & $\mathrm{H}$ & $\begin{array}{c}\text { Triple-zeta } \\
\mathrm{C}, \mathrm{N}, \mathrm{O}, \mathrm{S}\end{array}$ \\
\hline aug & $(\mathrm{s}, \mathrm{p})$ & $(\mathrm{s}, \mathrm{p}, \mathrm{d})$ & $(\mathrm{s}, \mathrm{p}, \mathrm{d})$ & $(\mathrm{s}, \mathrm{p}, \mathrm{d}, \mathrm{f})$ \\
jul & - & $(\mathrm{s}, \mathrm{p}, \mathrm{d})$ & - & $(\mathrm{s}, \mathrm{p}, \mathrm{d}, \mathrm{f})$ \\
jun & - & $(\mathrm{s}, \mathrm{p})$ & - & $(\mathrm{s}, \mathrm{p}, \mathrm{d})$ \\
may & - & $(\mathrm{s}, \mathrm{p})$ & - & $(\mathrm{s}, \mathrm{p})$ \\
++ & $(\mathrm{s})$ & $(\mathrm{s}, \mathrm{p})$ & $(\mathrm{s})$ & $(\mathrm{s}, \mathrm{p})$ \\
+ & - & $(\mathrm{s}, \mathrm{p})$ & - & $(\mathrm{s}, \mathrm{p})$ \\
\hline
\end{tabular}

functions [52]. Pople-type basis sets with "+" add diffuse s and p subshells only to nonhydrogen atoms and "++" sets also add diffuse s subshell to hydrogen atoms [40]. The diffuse functions included in the atoms using double and triple-zeta calendar and Pople basis sets, are given in Table 1. In case of double-zeta basis sets, jun represents a minimally augmented basis set and may is equivalent to jun.

\section{Results and Discussion}

\subsection{Thermal Contribution to the Gibbs Free Energy of Formation}

We have investigated the basis set convergence of the thermal contribution to the Gibbs free energy of formation for each of the reactions R1-R6. In this section thermochemical parameters have been calculated using rigid rotorharmonic oscillator approximations at $298.15 \mathrm{~K}$ and $1 \mathrm{~atm}$. All the individual thermal contributions to the Gibbs free energies for each reactions can be seen in the supporting information. We have calculated the Mean Absolute Errors (MAE) compared to the DFT/aug-cc-pV5Z level of theory for M062X, PW91, and $\omega$ B97X-D functionals.

In Table 2 the MAEs are presented for the correlation consistent and Def2-TZVP basis sets. There is little variation between the different basis sets in the thermal contribution to the Gibbs free energy. The M06-2X functional with the cc-pVDZ basis set yields the largest MAEs in the thermal contribution, with a maximum value $0.9 \mathrm{kcal} / \mathrm{mol}$. The largest MAEs for PW91 and $\omega$ B97X-D are $0.5-0.6 \mathrm{kcal} / \mathrm{mol}$. Both the hybrid-meta-GGA M06-2X and the range-separated $\omega$ B97X-D functionals, show erratic behavior with double-zeta basis sets, i.e., there is increasing error when adding diffuse 
Table 2: Mean Absolute Errors of the thermal contribution to the Gibbs free energy at $298.15 \mathrm{~K}$ and $1 \mathrm{~atm}(\mathrm{kcal} / \mathrm{mol})$ for correlation consistent basis sets compared to the DFT/aug-cc-pV5Z level of theory.

\begin{tabular}{lrrrrr}
\hline M06-2X & cc & may-cc & jun-cc & jul-cc & aug-cc \\
\hline pVDZ & 0.9 & 0.4 & 0.4 & 0.5 & 0.6 \\
pVTZ & 0.4 & 0.3 & 0.2 & 0.3 & 0.2 \\
pVQZ & 0.2 & 0.1 & 0.2 & 0.2 & 0.2 \\
pV5Z & 0.3 & 0.2 & 0.2 & 0.2 & 0.0 \\
pV6Z & 0.5 & & & & \\
Def2-TZVP & 0.2 & & & & \\
\hline PW91 & cc & may-cc & jun-cc & jul-cc & aug-cc \\
\hline pVDZ & 0.5 & 0.3 & 0.3 & 0.2 & 0.2 \\
pVTZ & 0.2 & 0.2 & 0.2 & 0.1 & 0.2 \\
pVQZ & 0.2 & 0.1 & 0.1 & 0.1 & 0.1 \\
pV5Z & 0.1 & 0.1 & 0.1 & 0.1 & 0.0 \\
pV6Z & 0.1 & & & & \\
Def2-TZVP & 0.3 & & & & \\
\hline wB97X-D & $\mathrm{cc}$ & may-cc & jun-cc & jul-cc & aug-cc \\
\hline pVDZ & 0.5 & 0.3 & 0.3 & 0.5 & 0.6 \\
pVTZ & 0.3 & 0.2 & 0.1 & 0.1 & 0.1 \\
pVQZ & 0.2 & 0.1 & 0.2 & 0.2 & 0.1 \\
pV5Z & 0.0 & 0.0 & 0.0 & 0.0 & 0.0 \\
pV6Z & 0.1 & & & & \\
Def2-TZVP & 0.2 & & & & \\
\hline
\end{tabular}

functions, with MAEs $0.5 \mathrm{kcal} / \mathrm{mol}$ with jul-cc-pVDZ and $0.6 \mathrm{kcal} / \mathrm{mol}$ with aug-cc-pVDZ. This is most likely due to error cancellation. Including diffuse functions regardless of augmentation level gives an accuracy comparable to one higher cardinal number, i.e., may-, jun-, jul-, and aug-cc-pVDZ yield results equivalent to cc-pVTZ. Especially, there is seen very little difference between the jul and aug basis sets which indicates that diffuse functions on hydrogen do not influence the results. Using $\omega$ B97X-D all the quintuple-zeta basis sets produce a MAE of $0.0 \mathrm{kcal} / \mathrm{mol}$, while PW91 and M06-2X yield MAEs in the range $0.1-0.3 \mathrm{kcal} / \mathrm{mol}$. For PW91 the Def2-TZVP basis set yield results slightly worse than cc-pVTZ, whereas the results for M06-2X and $\omega$ B97X-D are similar to cc-pVQZ.

The MAEs for Pople-type basis sets are presented in Table 3. For the 
Table 3: Mean Absolute Errors of the thermal contribution to the Gibbs free energy at $298.15 \mathrm{~K}$ and $1 \mathrm{~atm}(\mathrm{kcal} / \mathrm{mol})$ for Pople basis sets compared to the DFT/aug-cc-pV5Z level of theory.

\begin{tabular}{lrrrrr}
\hline M06-2X & $\mathrm{G}(\mathrm{d})$ & $+\mathrm{G}(\mathrm{d})$ & $++\mathrm{G}(\mathrm{d}, \mathrm{p})$ & $++\mathrm{G}(2 \mathrm{df}, 2 \mathrm{dp})$ & $++\mathrm{G}(3 \mathrm{df}, 3 \mathrm{dp})$ \\
\hline $6-31$ & 0.7 & 0.8 & 0.5 & 0.2 & 0.6 \\
6-311 & 1.1 & 0.9 & 0.7 & 0.3 & 0.3 \\
\hline PW91 & $\mathrm{G}(\mathrm{d})$ & $+\mathrm{G}(\mathrm{d})$ & $++\mathrm{G}(\mathrm{d}, \mathrm{p})$ & $++\mathrm{G}(2 \mathrm{df}, 2 \mathrm{dp})$ & $++\mathrm{G}(3 \mathrm{df}, 3 \mathrm{dp})$ \\
\hline $6-31$ & 0.5 & 0.6 & 0.3 & 0.2 & 0.2 \\
6-311 & 0.5 & 0.6 & 0.4 & 0.1 & 0.2 \\
\hline$\omega$ B97X-D & $\mathrm{G}(\mathrm{d})$ & $+\mathrm{G}(\mathrm{d})$ & $++\mathrm{G}(\mathrm{d}, \mathrm{p})$ & $++\mathrm{G}(2 \mathrm{df}, 2 \mathrm{dp})$ & $++\mathrm{G}(3 \mathrm{df}, 3 \mathrm{dp})$ \\
\hline 6-31 & 0.5 & 0.4 & 0.4 & 0.2 & 0.3 \\
6-311 & 0.6 & 0.6 & 0.4 & 0.2 & 0.3 \\
\hline
\end{tabular}

Pople basis sets increasing from a double to a triple-zeta basis set does not influence the MAEs. The M06-2X functional produces the largest MAEs with a maximum value of $1.1 \mathrm{kcal} / \mathrm{mol}$ for the $6-311 \mathrm{G}(\mathrm{d})$ basis set. PW91 and $\omega$ B97X-D both give MAEs between $0.1-0.6 \mathrm{kcal} / \mathrm{mol}$. The Pople basis sets also show erratic behavior with hybrid-meta-GGAs when increasing polarization functions from (2df,2dp) to (3df,3dp), indicating (as expected) no systematic basis set convergence. The first set of diffuse functions added to the heavy atoms $(+)$ show a decrease in the MAEs of $0.1-0.2 \mathrm{kcal} / \mathrm{mol}$. The further addition of polarization functions and diffuse functions to hydrogen decreases the MAEs by up to $0.4 \mathrm{kcal} / \mathrm{mol}$. A MAE increase of $0.2 \mathrm{kcal} / \mathrm{mol}$ or less is seen when changing from $6-311++\mathrm{G}(3 \mathrm{df}, 3 \mathrm{pd})$ to $6-31++\mathrm{G}(\mathrm{d}, \mathrm{p})$, which is consistent with our earlier study of thermal contributions for a large number of clusters [53]. 
Table 4: Mean Absolute Errors of the thermal contribution to the Gibbs free energy at $298.15 \mathrm{~K}$ and $1 \mathrm{~atm}(\mathrm{kcal} / \mathrm{mol})$ for polarization consistent basis sets compared to the DFT/aug-cc-pV5Z level of theory.

\begin{tabular}{lrrrr}
\hline M06-2X & 1 & 2 & 3 & 4 \\
\hline pc & 0.7 & 0.1 & 0.2 & 0.3 \\
aug-pc & 0.6 & 0.1 & & \\
\hline PW91 & 1 & 2 & 3 & 4 \\
\hline pc & 0.3 & 0.2 & 0.1 & 0.1 \\
aug-pc & 0.3 & 0.2 & & \\
\hline$\omega B 97 X-D$ & 1 & 2 & 3 & 4 \\
\hline pc & 0.4 & 0.1 & 0.2 & 0.1 \\
aug-pc & 0.5 & 0.2 & & \\
\hline
\end{tabular}

In Table 4 the MAEs are calculated for the polarization consistent basis sets. The highest value is $0.7 \mathrm{kcal} / \mathrm{mol}$ when using the M06-2X/pc-1 level of theory. The polarization consistent basis sets show a little bit faster convergence towards the complete basis set limit than the correlation consistent basis sets. Polarization consistent and correlation consistent basis sets appear to converge towards the same results as expected [54]. The pc-2 basis set yields results in good agreement with the large aug-cc-pV5Z basis.

Generally, it is seen that a small basis set is sufficient for calculating the thermal contribution to the Gibbs free energy of the investigated atmospheric clusters. A may-cc-pVDZ or $6-31++\mathrm{G}(\mathrm{d}, \mathrm{p})$ basis set might be sufficient for obtaining decent accuracy at a low computational cost. For higher accuracy, a triple-zeta basis set with some diffuse functions can be used if affordable. Going beyond a triple-zeta basis set would reduce the error to less than 0.3 $\mathrm{kcal} / \mathrm{mol}$.

\subsubsection{Extension to Larger Clusters}

To investigate whether the findings for the small complexes are still valid for larger clusters, we have calculated the thermal contributions for $\left(\mathrm{H}_{2} \mathrm{SO}_{4}\right)_{x}\left(\left(\mathrm{CH}_{3}\right)_{2} \mathrm{NH}\right)_{x}$ and $\left(\mathrm{H}_{2} \mathrm{SO}_{4}\right)_{x}\left(\mathrm{NH}_{3}\right)_{x}$ clusters, where $x=2$, 3, or 4 . For simplicity we will refer to $\mathrm{H}_{2} \mathrm{SO}_{4}$ as $\mathrm{A}, \mathrm{NH}_{3}$ as $\mathrm{N}$, and $\left(\mathrm{CH}_{3}\right)_{2} \mathrm{NH}$ as D. We only utilized a single functional PW91 and the basis sets which appeared to show promising results in the previous section, i.e., $6-31++\mathrm{G}^{* *}, 6-$ $311++\mathrm{G}(3 \mathrm{df}, 3 \mathrm{dp})$, may-cc-pVDZ, may-cc-pVTZ, and aug-cc-pVTZ are tested. All the values have been calculated using rigid rotor-harmonic oscillator ap- 


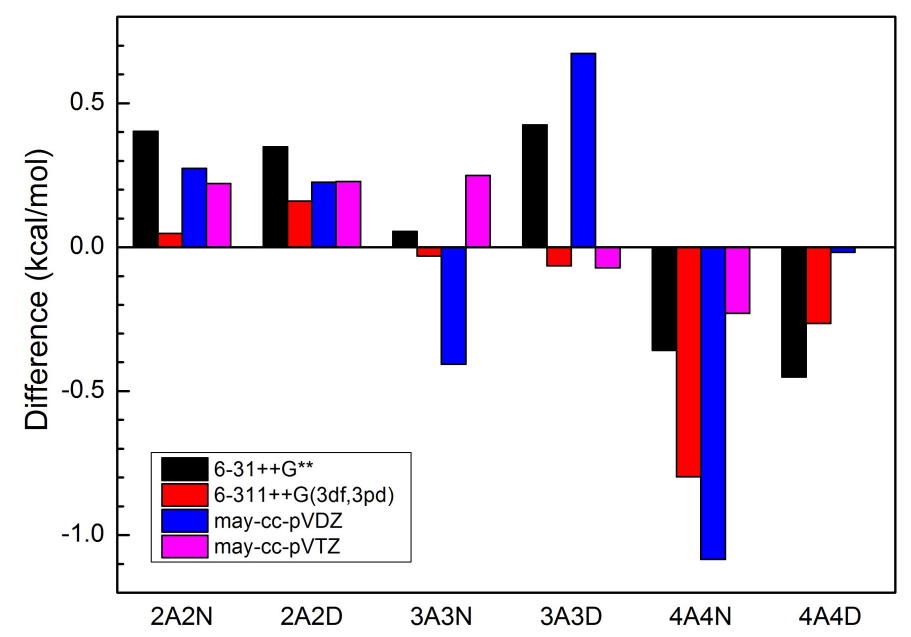

Figure 1: Thermal contribution difference between $6-31++\mathrm{G}^{* *}, 6-311++\mathrm{G}(3 \mathrm{df}, 3 \mathrm{dp})$, maycc-pVDZ, and may-cc-pVTZ relative to aug-cc-pVTZ (in case of 4A4D relative to maycc-pVTZ). We refer $\mathrm{H}_{2} \mathrm{SO}_{4}$ as $\mathrm{A}, \mathrm{NH}_{3}$ as $\mathrm{N}$, and $\left(\mathrm{CH}_{3}\right)_{2} \mathrm{NH}$ as D. Calculations were done using the PW91 functional at $298.15 \mathrm{~K}$ and 1 atm.

proximations at $298.15 \mathrm{~K}$ and 1 atm. Figure 1 presents the difference of the thermal contributions to the Gibbs free energy between $6-31++\mathrm{G}^{* *}$, 6-311++G(3df,3dp), may-cc-pVDZ, and may-cc-pVTZ, relative to aug-ccpVTZ. The largest cluster $\left(\mathrm{H}_{2} \mathrm{SO}_{4}\right)_{4}\left(\left(\mathrm{CH}_{3}\right)_{2} \mathrm{NH}\right)_{4}$ was computationally too demanding with the aug-cc-pVTZ basis set, therefore, we compared the results to the may-cc-pVTZ value. The $6-31++\mathrm{G}^{* *}$ basis shows good agreement relative to aug-cc-pVTZ, with a maximum error of $0.4 \mathrm{kcal} / \mathrm{mol}$. Maycc-pVDZ produces the largest maximum error of $1.1 \mathrm{kcal} / \mathrm{mol}$, for the $4 \mathrm{~A} 4 \mathrm{~N}$ cluster. May-cc-pVTZ basis set yields the lowest maximum error of 0.2 $\mathrm{kcal} / \mathrm{mol}$. Generally, it is seen that the results for the small molecular clusters are still valid for larger ones, and small basis sets are thereby sufficient for calculating the thermal contributions to the Gibbs free energy. 


\subsubsection{Quasi-Harmonic Approximation}

The thermal correction to the Gibbs free energy (Eq. 4) is calculated as follows:

$$
G_{\text {corr }}=H_{\text {corr }}-T S_{\text {tot }}
$$

where $H_{\text {corr }}$ is thermal correction to the enthalpy including the zero point energy, $T$ is the absolute temperature, and $S_{\text {tot }}$ is the total entropy. The vibrational entropy of a harmonic oscillator with frequency $\omega$ is given in equation 5 :

$$
S_{\mathrm{V}}=R\left[\frac{h \omega}{k\left(e^{h \omega / k T}-1\right)}-\ln \left(1-e^{-h \omega / k T}\right)\right]
$$

where $R$ is the gas constant, $h$ is Planck's constant, and $k$ is Boltzmann's constant. The second term of equation 5 approaches asymptotically infinity for $\omega \rightarrow 0$ and the harmonic approximation becomes inaccurate for low frequencies. The literature suggests several approaches to correct vibrational entropies of low-lying frequencies $[55,56,57]$ and here we focus on the quasiharmonic approximation, as recommended by Grimme [20], where the contribution of low frequencies to the entropy is replaced by a corresponding rotational entropy (Eq. 6):

$$
S_{\mathrm{R}}=R\left\{\frac{1}{2}+\ln \left[\left(\frac{8 \pi^{3} \mu^{\prime} k T}{h^{2}}\right)^{1 / 2}\right]\right\}
$$

where $\mu^{\prime}$ is an effective moment of inertia, calculated from the moment of inertia $\mu$ for a free-rotor and the average moment of inertia $B_{a v}$ as equation 7. An effective moment of inertia is restricted to reasonable values by using $B_{a v}=10^{-44} \mathrm{~kg} \mathrm{~m}^{2}$ as a limiting value for very small $\omega[20]$.

$$
\mu^{\prime}=\frac{\mu B_{a v}}{\mu+B_{a v}}
$$

The resulting vibrational entropy is interpolated between $S_{\mathrm{V}}$ and $S_{\mathrm{R}}$ with a cut-off frequency of $100 \mathrm{~cm}^{-1}$, as proposed in the literature.[58, 59]

We have calculated thermal contributions to the Gibbs free energy using the quasi-harmonic approximation for $\left(\mathrm{H}_{2} \mathrm{SO}_{4}\right)_{x}\left(\left(\mathrm{CH}_{3}\right)_{2} \mathrm{NH}\right)_{x}$ and $\left(\mathrm{H}_{2} \mathrm{SO}_{4}\right)_{x}\left(\mathrm{NH}_{3}\right)_{x}$ clusters, where $x=2-4$. The quasi-harmonic calculations are performed using the Python script GoodVibes.py by Prof. Robert Paton[60]. We used the PW91 functional with the 6-31++G**, 6-311++G(3df,3dp), may-cc-pVDZ, may-cc-pVTZ, and aug-cc-pVTZ basis sets. The difference between RRHO 


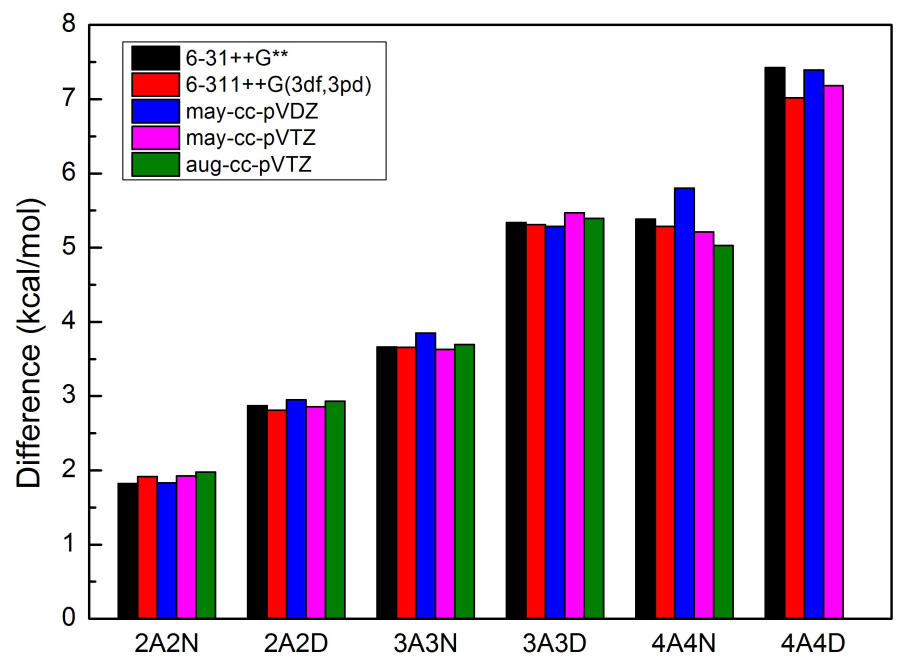

Figure 2: Difference between RRHO and quasi-RRHO thermal contributions to the Gibbs free energy $(\mathrm{kcal} / \mathrm{mol})$. Calculations were done using the PW91 functional with double and triple-zeta basis sets at $298.15 \mathrm{~K}$ and $1 \mathrm{~atm}$. Abbreviations: $\mathrm{A}=\mathrm{H}_{2} \mathrm{SO}_{4}, \mathrm{~N}=\mathrm{NH}_{3}$, and $\mathrm{D}=\left(\mathrm{CH}_{3}\right)_{2} \mathrm{NH}$.

and quasi-RRHO approaches can be seen in Figure 2. The quasi-RRHO value will always be greater than (or equal to) the RRHO thermal contribution to the Gibbs free energy since the vibrational entropy associated with the low-lying vibrational modes is reduced in this approach. The errors look more or less the same with different basis sets. For the smallest cluster, $\left(\mathrm{H}_{2} \mathrm{SO}_{4}\right)_{2}\left(\mathrm{NH}_{3}\right)_{2}$, the difference between the harmonic and quasi-harmonic approximation is $1.8-2.0 \mathrm{kcal} / \mathrm{mol}$. The error increases when increasing the system size, and is always between $4.9-8.0 \%$ of the harmonic thermal contribution (for the studied clusters). Therefore, the largest error for the $\left(\mathrm{H}_{2} \mathrm{SO}_{4}\right)_{4}\left(\left(\mathrm{CH}_{3}\right)_{2} \mathrm{NH}\right)_{4}$ cluster is found to be $7.0-7.4 \mathrm{kcal} / \mathrm{mol}$.

\subsubsection{Anharmonic Scale Factors}

To quantify the effect of vibrational anharmonicity and derive scale factors to correct for it, we used both the clusters and the monomers in reactions R1-R6, i.e., a total of 11 systems. This implies the evaluation of 252 individual vibrational modes. The anharmonic calculations were performed using second order vibrational perturbation theory (VPT2)[26, 61, 62], using a tight convergence criteria and an ultrafine grid. We tested all three function- 

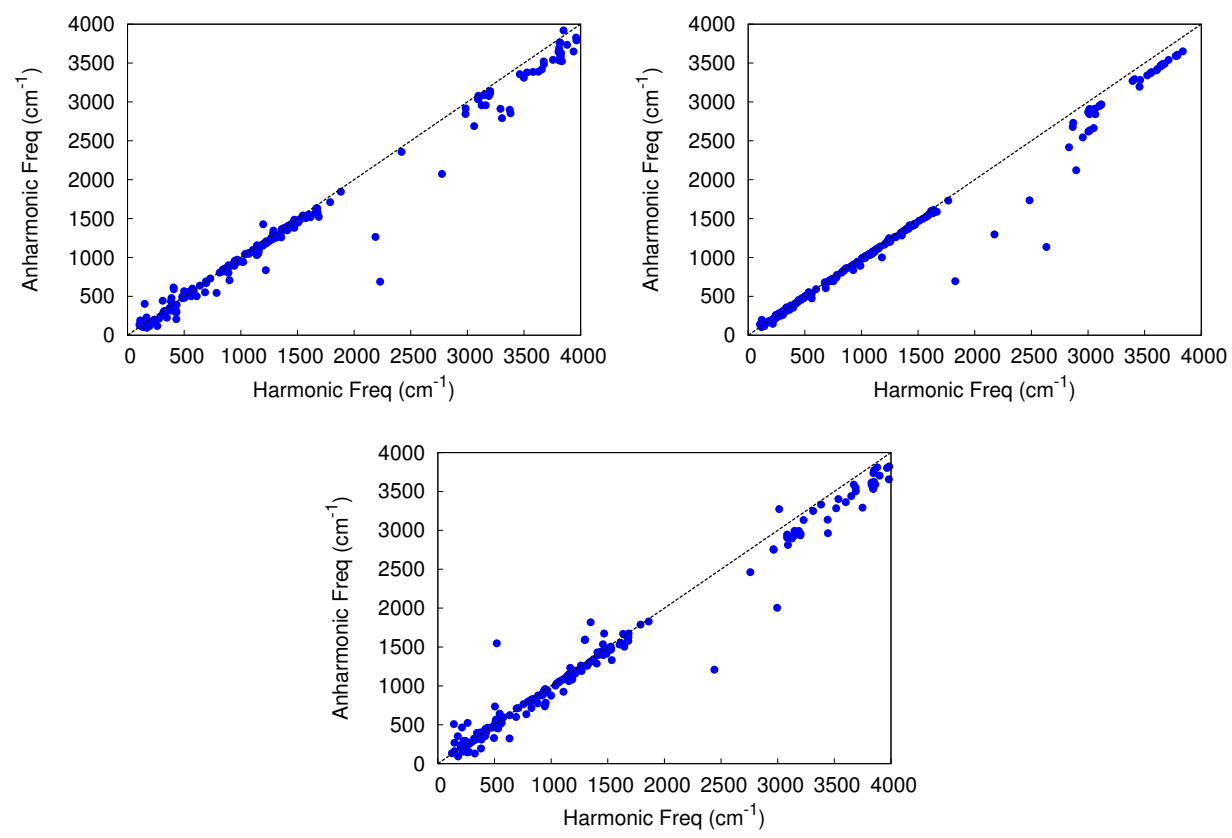

Figure 3: Correlation between the harmonic and anharmonic frequencies (in $\mathrm{cm}^{-1}$ ) calculated with M06-2X (top, left), PW91 (top, right), and $\omega$ B97X-D (down) with the 6$31++\mathrm{G}(\mathrm{d}, \mathrm{p})$ basis set.

als with the 6-31G(d), 6-31+G(d), 6-31++G(d,p), and may-cc-pVDZ basis sets. For PW91 the large 6-311++G(3df,3pd) basis set was also tested, due to its popularity for calculating the geometries of molecular clusters in the literature [63, 64, 65]. All vibrational frequencies below $100 \mathrm{~cm}^{-1}$ were removed as these do not correspond to real vibrational frequencies and should rather be treated as rotations instead (see previous section for more details). A few anomalous imaginary anharmonic frequencies were identified and removed from the analysis. The number of spurious frequencies was largest for the meta-GGA functionals, M06-2X and $\omega$ B97X-D, compared to the PW91 functional. Figure 3 shows the correlation between the harmonic and anharmonic frequencies calculated with the $6-31++\mathrm{G}(\mathrm{d}, \mathrm{p})$ basis set.

The vibrational frequencies below $2000 \mathrm{~cm}^{-1}$ have a correlation close to unity. The calculated anharmonic frequencies above $3000 \mathrm{~cm}^{-1}$ are consistently lower than the corresponding harmonic frequencies. The frequencies in the range $2000-3000 \mathrm{~cm}^{-1}$ generally have large outliers, indicating there is 
Table 5: The mean scaling factors derived for M06-2X, PW91, and $\omega$ B97X-D functionals using different basis sets.

\begin{tabular}{lrrr}
\hline Method & M06-2X & PW91 & $\omega$ B97X-D \\
\hline 6-31G(d) & 0.9695 & 0.9544 & 0.9812 \\
6-31+G(d) & 0.9773 & 0.9527 & 0.9884 \\
6-31++G(d,p) & 0.9598 & 0.9572 & 0.9960 \\
may-cc-pVDZ & 0.9673 & 0.9591 & 0.9405 \\
6-311++G(3df,3pd) & - & 0.9499 & - \\
\hline
\end{tabular}

a large, but not systematic, effect from including anharmonicity. These vibrations are typically the stretching motion along a hydrogen bond towards the acceptor atom. To correct for anharmonicity we estimate the scaling factor between the anharmonic and harmonic frequencies. Table 5 presents the calculated scaling factors over the entire range of frequencies.

The scaling factors lie in the range 0.9405 to 0.9960 depending on the basis set and functional utilized. To determine what effect the scaling of the harmonic vibrational frequencies has on the Gibbs free energies, we used a test set comprised of $\left(\mathrm{H}_{2} \mathrm{SO}_{4}\right)_{a}\left(\mathrm{NH}_{3}\right)_{b}$ and $\left(\mathrm{H}_{2} \mathrm{SO}_{4}\right)_{a}\left(\left(\mathrm{CH}_{3}\right)_{2} \mathrm{NH}\right)_{b}$ clusters, with $a, b \leq 4$ extracted from Ortega et al.[66]. The clusters were geometry optimized using the M06-2X, PW91, and $\omega$ B97X-D functionals with a 6$31++\mathrm{G}(\mathrm{d}, \mathrm{p})$ basis set using a tight convergence criteria and an ultrafine grid. The thermal contribution to the free energy have then been calculated both with and without using the scaling factors derived in Table 5. The effect of scaling factors on the thermal contribution to the Gibbs free energy is found to be small. For $\omega \mathrm{B} 97 \mathrm{X}-\mathrm{D}$ the scaling factor is essential unity, and the largest effect on the thermal contribution is found to be a lowering of $0.21 \mathrm{kcal} / \mathrm{mol}$. For M06-2X and PW91, the largest effect is a lowering of $1.18 \mathrm{kcal} / \mathrm{mol}$ and $2.03 \mathrm{kcal} / \mathrm{mol}$, respectively. The effect of vibrational anharmonicity on these hydrogen-bonded clusters is thereby seen to be rather small, regardless of the system size, provided that the low frequencies are treated separately.

We calculated thermal contribution to the Gibbs free energy using a combination of quasi-harmonic and anharmonic approximations at the PW91/6$311++\mathrm{G}(3 \mathrm{df}, 3 \mathrm{pd})$ level of theory for $\left(\mathrm{H}_{2} \mathrm{SO}_{4}\right)_{x}\left(\left(\mathrm{CH}_{3}\right)_{2} \mathrm{NH}\right)_{x}$ and $\left(\mathrm{H}_{2} \mathrm{SO}_{4}\right)_{x}\left(\mathrm{NH}_{3}\right)_{x}$ clusters, where $x=2-4$. The effect of quasi-harmonic and anharmonic corrections and their combination is calculated using a $100 \mathrm{~cm}^{-1}$ cut-off value and 0.9499 anharmonic scaling factor for frequencies above this. Figure 4 shows that the low-lying frequencies, which are treated as free rotors, have the 


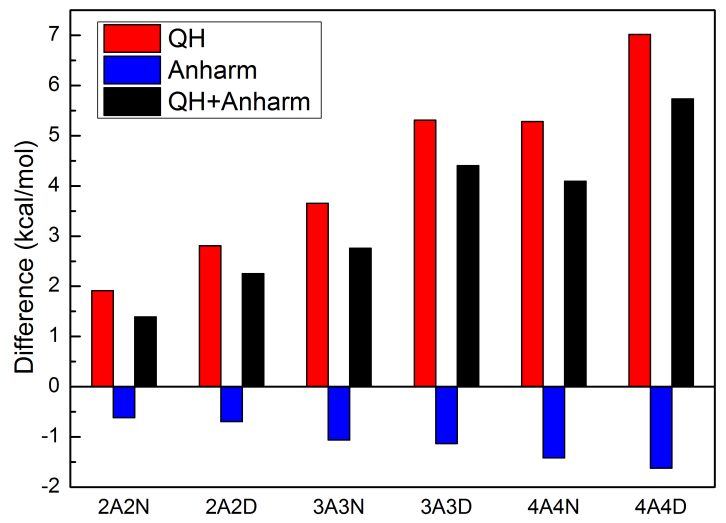

Figure 4: Difference between the RRHO thermal contributions and quasi-harmonic, anharmonic, and combination of quasi-harmonic and anharmonic approximations. Calculations were prformed at PW91/6-311++G(3df,3pd) level of theory at $298.15 \mathrm{~K}$ and $1 \mathrm{~atm}$. Abbreviations: $\mathrm{A}=\mathrm{H}_{2} \mathrm{SO}_{4}, \mathrm{~N}=\mathrm{NH}_{3}$, and $\mathrm{D}=\left(\mathrm{CH}_{3}\right)_{2} \mathrm{NH}$.

largest impact on the thermal contribution. For the $\left(\mathrm{H}_{2} \mathrm{SO}_{4}\right)_{4}\left(\left(\mathrm{CH}_{3}\right)_{2} \mathrm{NH}\right)_{4}$ cluster, the quasi-harmonic approximation yields a $7.0 \mathrm{kcal} / \mathrm{mol}$ higher thermal contribution, the anharmonic approximation yields a $1.6 \mathrm{kcal} / \mathrm{mol}$ lower thermal contribution, and the combination of them increases the thermal contribution by $5.7 \mathrm{kcal} / \mathrm{mol}$. The effect of vibrational anharmonicity is a mere $1.6-1.7 \%$ lowering compared to the total harmonic thermal contribution. The quasi-harmonic approximation increases the contribution by up to $7.8 \%$. The combination of both leads to an increases of $3.8-6.4 \%$ in the thermal contribution.

Overall it appears, that treating low-lying frequencies as free rotors and scaling the remaining frequencies using the derived scale factors in Table 5 yield a practical approach for empirically correcting the rigid rotor harmonic oscillator approximation. This approach does not require any extra computational resources and therefore is also available for larger clusters, where anharmonic VPT2 calculations are out of reach. 


\subsection{Binding Energy}

We have investigated the basis set convergence of the cluster binding energies. All the individual binding energies for each reaction are available in the supporting information. We have calculated the Mean Absolute Error (MAE) compared to the DFT/aug-cc-pV5Z level of theory for the M06-2X, PW91, and $\omega$ B97X-D functionals.

There is a large scatter in the calculated binding energies depending on what basis set is utilized, with MAEs of up to $7.2 \mathrm{kcal} / \mathrm{mol}$ for the PW91/ccpVDZ level of theory (see Table 6). Adding diffuse functions effectively increases the basis set convergence by 1-2 cardinal numbers. However, there is very little effect from adding diffuse functions to the hydrogen atoms, as demonstrated by the small difference between the aug-cc and jul-cc basis sets. When using a double-zeta basis set with may or jun, it gives twice the MAE as jul or aug. This could indicate that adding a single diffuse $d$ function greatly improves the basis set convergence of the binding energy. The Def2-TZVP basis set effectively yield results in between cc-pVTZ and cc-pVQZ for all three functionals.

The Pople-type basis sets show a higher MAE in the binding energies compared to the correlation consistent basis sets (see Table 7). For all functionals, triple-zeta basis sets produce higher MAEs than double-zeta sets when adding only $\mathrm{G}(\mathrm{d})$ or $+\mathrm{G}(\mathrm{d})$. The $6-31++\mathrm{G}(\mathrm{d}, \mathrm{p})$ basis set shows errors in the range $2.2-2.4 \mathrm{kcal} / \mathrm{mol}$. Even when increasing to the large 6$311++\mathrm{G}(3 \mathrm{df}, 3 \mathrm{pd})$ basis set, the MAE in the binding energy is still in the range $0.6-0.9 \mathrm{kcal} / \mathrm{mol}$. This indicates that $\mathrm{DFT} / 6-311++\mathrm{G}(3 \mathrm{df}, 3 \mathrm{pd})$ results might not have reached satisfactory basis set convergence, and even double-zeta correlation consistent basis set with jul or aug functions yield a results closer to the complete basis set limit.

The pc- 1 basis set shows MAEs in the range $4.6-5.5 \mathrm{kcal} / \mathrm{mol}$, which is reduces to $0.7-0.9 \mathrm{kcal} / \mathrm{mol}$ with the pc-2 basis set (see Table 8 ). The pc-3 and aug-pc-2 basis sets show results close to the complete basis set limit, with a slightly faster convergence than for the correlation consistent basis sets.

In most of the cases reaction $\mathrm{R} 5$ yields the largest error to the binding energy. Especially when using small basis set the error of reaction R5 might be twice as large as the MAE. Removing reaction R5 from MAE calculation decreases the value of the MAE, but qualitative results and trends remain the same. 
Table 6: Mean Absolute Errors in the binding energy (kcal/mol) compared to the DFT/aug-cc-pV5Z level of theory for correlation consistent basis sets.

\begin{tabular}{lrrrrr}
\hline M06-2X & cc & may-cc & jun-cc & jul-cc & aug-cc \\
\hline pVDZ & 5.1 & 1.0 & 1.0 & 0.5 & 0.5 \\
pVTZ & 1.7 & 0.3 & 0.2 & 0.2 & 0.3 \\
pVQZ & 0.5 & 0.0 & 0.1 & 0.1 & 0.1 \\
pV5Z & 0.1 & 0.1 & 0.1 & 0.1 & 0.0 \\
pV6Z & 0.1 & & & & \\
Def2-TZVP & 0.8 & & & & \\
\hline PW91 & cc & may-cc & jun-cc & jul-cc & aug-cc \\
\hline pVDZ & 7.2 & 1.1 & 1.1 & 0.6 & 0.4 \\
pVTZ & 2.3 & 0.2 & 0.1 & 0.1 & 0.1 \\
pVQZ & 1.1 & 0.0 & 0.0 & 0.0 & 0.1 \\
pV5Z & 0.3 & 0.0 & 0.0 & 0.0 & 0.0 \\
pV6Z & 0.1 & & & & \\
Def2-TZVP & 1.4 & & & & \\
\hline$\omega$ B97X-D & $\mathrm{cc}$ & may-cc & jun-cc & jul-cc & aug-cc \\
\hline pVDZ & 5.3 & 1.2 & 1.2 & 0.5 & 0.5 \\
pVTZ & 1.8 & 0.4 & 0.3 & 0.3 & 0.3 \\
pVQZ & 0.7 & 0.0 & 0.0 & 0.0 & 0.1 \\
pV5Z & 0.2 & 0.0 & 0.0 & 0.0 & 0.0 \\
pV6Z & 0.1 & & & & \\
Def2-TZVP & 1.0 & & & & \\
\hline
\end{tabular}

Table 7: Mean Absolute Errors in the binding energy (kcal/mol) compared to the DFT/aug-cc-pV5Z level of theory for Pople basis sets.

\begin{tabular}{lrrrrr}
\hline M06-2X & $\mathrm{G}(\mathrm{d})$ & $+\mathrm{G}(\mathrm{d})$ & $++\mathrm{G}(\mathrm{d}, \mathrm{p})$ & $++\mathrm{G}(2 \mathrm{df}, 2 \mathrm{dp})$ & $++\mathrm{G}(3 \mathrm{df}, 3 \mathrm{dp})$ \\
\hline $6-31$ & 4.8 & 2.8 & 2.3 & 0.4 & 0.7 \\
$6-311$ & 6.0 & 4.1 & 2.3 & 0.3 & 0.6 \\
\hline PW91 & $\mathrm{G}(\mathrm{d})$ & $+\mathrm{G}(\mathrm{d})$ & $++\mathrm{G}(\mathrm{d}, \mathrm{p})$ & $++\mathrm{G}(2 \mathrm{df}, 2 \mathrm{dp})$ & $++\mathrm{G}(3 \mathrm{df}, 3 \mathrm{dp})$ \\
\hline $6-31$ & 6.0 & 2.6 & 2.2 & 0.9 & 0.9 \\
$6-311$ & 6.7 & 3.6 & 1.9 & 0.6 & 0.9 \\
\hline$\omega$ B97X-D & $\mathrm{G}(\mathrm{d})$ & $+\mathrm{G}(\mathrm{d})$ & $++\mathrm{G}(\mathrm{d}, \mathrm{p})$ & $++\mathrm{G}(2 \mathrm{df}, 2 \mathrm{dp})$ & $++\mathrm{G}(3 \mathrm{df}, 3 \mathrm{dp})$ \\
\hline 6-31 & 4.9 & 2.7 & 2.4 & 0.8 & 0.9 \\
6-311 & 5.9 & 3.9 & 2.4 & 0.7 & 0.9 \\
\hline
\end{tabular}


Table 8: Mean Absolute Errors in the binding energy ( $\mathrm{kcal} / \mathrm{mol}$ ) compared to the DFT/aug-cc-pV5Z level of theory for polarization consistent basis sets.

\begin{tabular}{lrrrr}
\hline M06-2X & 1 & 2 & 3 & 4 \\
\hline pc & 4.6 & 0.7 & 0.2 & 0.2 \\
aug-pc & 1.8 & 0.3 & & \\
\hline PW91 & 1 & 2 & 3 & 4 \\
\hline pc & 5.5 & 0.9 & 0.1 & 0.0 \\
aug-pc & 1.6 & 0.2 & & \\
\hline$\omega$ B97X-D & 1 & 2 & 3 & 4 \\
\hline pc & 4.6 & 0.8 & 0.0 & 0.0 \\
aug-pc & 1.6 & 0.2 & & \\
\hline
\end{tabular}

Using a may-cc-pVTZ basis set yields results close to the basis set limit. For even higher accuracy, a may-cc-pVQZ basis set could be used for calculating the binding energies, if computational feasible, and if high level coupled cluster methods can not be used.

\subsubsection{Extension to Larger Clusters}

To study whether the results for the small clusters are still valid for larger ones, we have calculated binding energies for $\left(\mathrm{H}_{2} \mathrm{SO}_{4}\right)_{x}\left(\left(\mathrm{CH}_{3}\right)_{2} \mathrm{NH}\right)_{x}$ and $\left(\mathrm{H}_{2} \mathrm{SO}_{4}\right)_{x}\left(\mathrm{NH}_{3}\right)_{x}$ clusters, where $x=2-4$, using the PW91 functional with 6-31++G**, 6-311++G(3df,3dp), may-cc-pVDZ, may-cc-pVTZ, and augcc-pVTZ basis sets. Figure 5 shows the calculated binding energy differences relative to aug-cc-pVTZ (due to computational restrictions in case the $4 \mathrm{~A} 4 \mathrm{D}$ cluster relative to may-cc-pVTZ). There is a large scatter in the binding energies when using different basis sets, up to $19.2 \mathrm{kcal} / \mathrm{mol}$ for the $\left(\mathrm{H}_{2} \mathrm{SO}_{4}\right)_{4}\left(\mathrm{NH}_{3}\right)_{4}$ cluster and $19.5 \mathrm{kcal} / \mathrm{mol}$ for the $\left(\mathrm{H}_{2} \mathrm{SO}_{4}\right)_{4}\left(\left(\mathrm{CH}_{3}\right)_{2} \mathrm{NH}\right)_{4}$ cluster with the $6-31++\mathrm{G}^{* *}$ basis set. The larger Pople-type basis set 6 $311++\mathrm{G}(3 \mathrm{df}, 3 \mathrm{dp})$ yields errors in the range $2.4-7.7 \mathrm{kcal} / \mathrm{mol}$ showing, as in the previous section, that these results are not even close to basis set convergence. It is observed that at least a may-cc-pVTZ basis set is required to yield errors in the binding energies below $2 \mathrm{kcal} / \mathrm{mol}$.

\subsubsection{Counterpoise Correction}

The simplest approach to calculate the dimer binding energy is to calculate the dimer energy and substract the energies of isolated monomers, as indicated by equation 1 . However, basis functions from one molecule can 


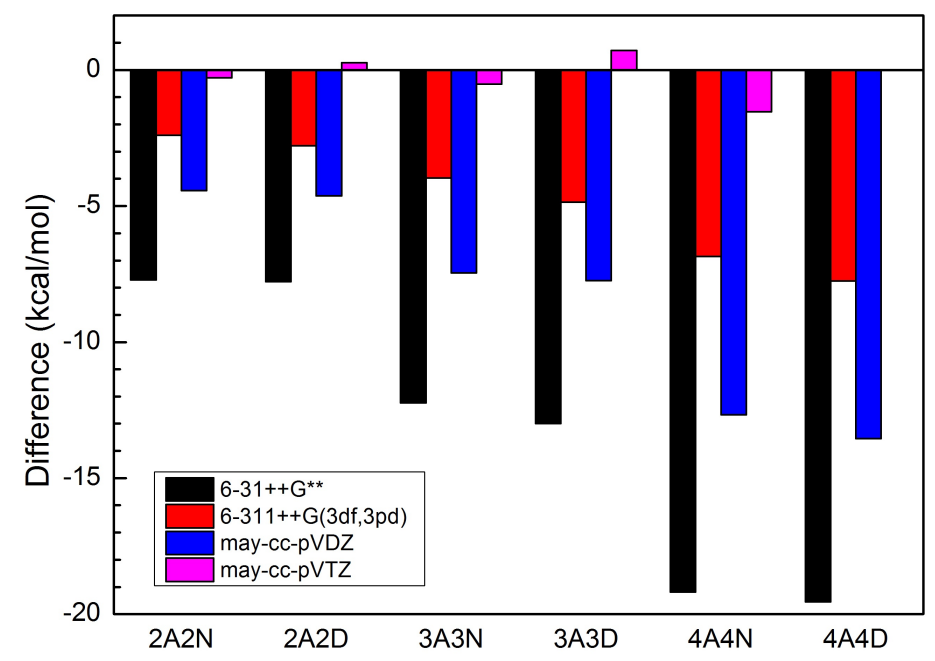

Figure 5: Binding energy differences between 6-31++G**, 6-311++G(3df,3dp), may-ccpVDZ, and may-cc-pVTZ relative to aug-cc-pVTZ (and in case of $4 \mathrm{~A} 4 \mathrm{D}$ relative to maycc-pVTZ) calculated using PW91 functional. Abbreviations: $\mathrm{A}=\mathrm{H}_{2} \mathrm{SO}_{4}, \mathrm{~N}=\mathrm{NH}_{3}$, and $\mathrm{D}=\left(\mathrm{CH}_{3}\right)_{2} \mathrm{NH}$.

help compensate for the basis set incompleteness on the other molecule in the dimer. Therefore, the dimer will be artificially too stable, and the difference is known as the Basis Set Superposition Error (BSSE) [67]. In the limit of a complete basis set, the BSSE will be zero, but in practice this requires very large basis sets. An approximate way of assessing BSSE is the counterpoise (CP) correction [68]. We have calculated CP corrected binding energies as follows:

$$
\Delta E_{\text {binding }}^{\mathrm{CP}}=\Delta E_{\text {binding }}+E_{\mathrm{AB}}^{\mathrm{A}}(\mathrm{A})+E_{\mathrm{AB}}^{\mathrm{B}}(\mathrm{B})-E_{\mathrm{AB}}^{\mathrm{AB}}(\mathrm{A})-E_{\mathrm{AB}}^{\mathrm{AB}}(\mathrm{B})
$$

where $\Delta E_{\text {binding }}$ is calculated as in Eq. $1, E_{\mathrm{AB}}^{\mathrm{A}}(\mathrm{A})$ and $E_{\mathrm{AB}}^{\mathrm{B}}(\mathrm{B})$ are energies for monomers $\mathrm{A}$ and $\mathrm{B}$ calculated with the geometry they have in the dimer, and $E_{\mathrm{AB}}^{\mathrm{AB}}(\mathrm{A})$ and $E_{\mathrm{AB}}^{\mathrm{AB}}(\mathrm{B})$ are energies for monomers $\mathrm{A}$ and $\mathrm{B}$ calculated at the dimer geometry and with the full dimer basis set.

To illustrate the effect of the counterpoise correction, we have calculated binding energies with and without the CP correction at the PW91/maycc-pVxZ level of theory for the sulfuric acid dimer (see Figure 6). When using a double-zeta basis set, the basis set superposition error (BSSE) is 2.0 


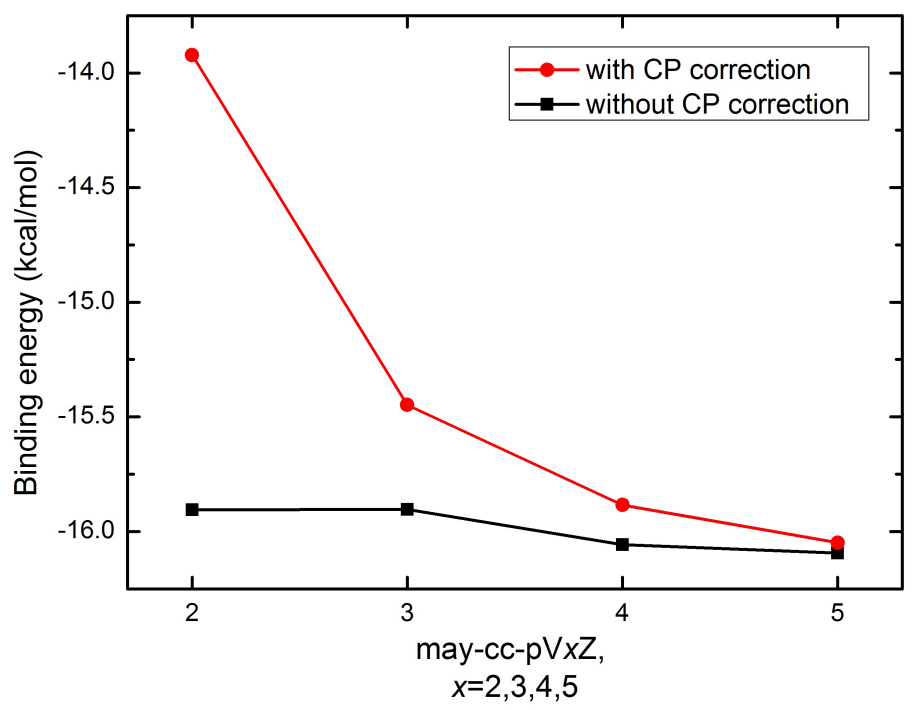

Figure 6: Binding energies with and without counterpoise correction for sulfuric acid dimer calculated with PW91/may-cc-pV $x \mathrm{Z}$ level of theory, where cardinal number $x$ is presented as the $x$-axis.

$\mathrm{kcal} / \mathrm{mol}$, and it reduces to $0.5 \mathrm{kcal} / \mathrm{mol}$ at the triple-zeta level. With a quadruple-zeta basis set the BSSE is $0.2 \mathrm{kcal} / \mathrm{mol}$ and with quintuple-zeta it is negligible.

Although the BSSE for double and triple-zeta is large, the uncorrected values correspond better to the complete basis set limit than the $\mathrm{CP}$ corrected ones for sulfuric acid dimer. This indicates, that in contrast to what the $\mathrm{CP}$ correction indicates, even a may-cc-pVDZ basis set gives a low error, 0.2 $\mathrm{kcal} / \mathrm{mol}$, compared to the may-cc-pV5Z value. Therefore, for hydrogenbonded clusters, uncorrected binding energies should be used for smaller basis sets. However, the CP corrected binding energies smoothly converge towards a specific value, whereas the uncorrected values first appear to have the same binding energy for double and triple-zeta, and then decrease a bit for quadruple and quintuple-zeta basis sets. Therefore, when doing basis set extrapolations using DFT binding energies, counterpoise corrected binding energies might be required. 


\subsection{The Effect of Geometry}

To investigated how different basis sets used to optimize the geometry affect the subsequent calculation of the binding energies, we have calculated single point energies on top of the DFT geometries using DLPNOCCSD(T)/def2-QZVPP level of theory, here simply referred to as DLPNO. All the individual DLPNO binding energies for each reaction can be seen in the supporting information.

The MAEs for the correlation consistent and Def2-TZVP basis sets compared to DLPNO//DFT/aug-cc-pV5Z results are presented in Table 9. The MAE is found to be up to $1.3 \mathrm{kcal} / \mathrm{mol}$ when the geometry is optimized at M06-2X/cc-pVDZ level of theory. The M06-2X functional yields the highest MAEs as expected due to its slow basis set convergence[69]. However, PW91 shows fast convergence and may-cc-pVDZ results correspond well the augcc-pV5Z results. For every functional may-cc-pVTZ yields good agreement with the large aug-cc-pV5Z basis set, producing errors of $0.3 \mathrm{kcal} / \mathrm{mol}$ or less. The Def2-TZVP basis set is seen to perform well, with MAEs similar to cc-pVQZ or better.

With Pople-type basis sets, the PW91 and $\omega$ B97X-D functionals give good results when using a $6-31+\mathrm{G}(\mathrm{d})$ basis set, with a MAE of only 0.3 $\mathrm{kcal} / \mathrm{mol}$ (see Table 10). However, the M06-2X functional requires a slightly larger basis set, 6-31++G(2df,2dp), to yield good agreement with the augcc-pV5Z basis set. There is only observed a small difference between double and triple-zeta basis sets, and the effect of polarization and diffuse functions is dominanting over the effect of cardinal number. 
Table 9: Mean Absolute Errors of the DLPNO-CCSD(T)/def2-QZVPP//DFT/basis binding energy $(\mathrm{kcal} / \mathrm{mol})$ for correlation consistent basis sets compared to the DLPNO//DFT/aug-cc-pV5Z level of theory.

\begin{tabular}{lrrrrr}
\hline M06-2X & cc & may-cc & jun-cc & jul-cc & aug-cc \\
\hline pVDZ & 1.3 & 0.7 & 0.7 & 0.5 & 0.5 \\
pVTZ & 0.5 & 0.3 & 0.3 & 0.3 & 0.3 \\
pVQZ & 0.3 & 0.3 & 0.3 & 0.3 & 0.3 \\
pV5Z & 0.0 & 0.0 & 0.0 & 0.0 & 0.0 \\
pV6Z & 0.0 & & & & \\
Def2-TZVP & 0.1 & & & & \\
\hline PW91 & cc & may-cc & jun-cc & jul-cc & aug-cc \\
\hline pVDZ & 0.9 & 0.1 & 0.1 & 0.1 & 0.2 \\
pVTZ & 0.2 & 0.1 & 0.1 & 0.1 & 0.1 \\
pVQZ & 0.1 & 0.0 & 0.0 & 0.0 & 0.0 \\
pV5Z & 0.0 & 0.0 & 0.0 & 0.0 & 0.0 \\
pV6Z & 0.0 & & & & \\
Def2-TZVP & 0.1 & & & & \\
\hline$\omega B 97 X-D$ & $c c$ & may-cc & jun-cc & jul-cc & aug-cc \\
\hline pVDZ & 0.6 & 0.4 & 0.4 & 0.2 & 0.2 \\
pVTZ & 0.3 & 0.2 & 0.3 & 0.2 & 0.2 \\
pVQZ & 0.1 & 0.1 & 0.1 & 0.1 & 0.1 \\
pV5Z & 0.0 & 0.0 & 0.0 & 0.0 & 0.0 \\
pV6Z & 0.0 & & & & \\
Def2-TZVP & 0.0 & & & & \\
\hline
\end{tabular}

Table 10: Mean Absolute Errors of the DLPNO-CCSD(T)/def2-QZVPP//DFT/basis binding energy $(\mathrm{kcal} / \mathrm{mol}$ ) for Pople basis sets compared to the DLPNO//DFT/aug-ccpV5Z level of theory.

\begin{tabular}{lrrrrr}
\hline M06-2X & $\mathrm{G}(\mathrm{d})$ & $+\mathrm{G}(\mathrm{d})$ & $++\mathrm{G}(\mathrm{d}, \mathrm{p})$ & $++\mathrm{G}(2 \mathrm{df}, 2 \mathrm{dp})$ & $++\mathrm{G}(3 \mathrm{df}, 3 \mathrm{dp})$ \\
\hline $6-31$ & 0.8 & 0.6 & 0.7 & 0.3 & 0.2 \\
$6-311$ & 0.8 & 0.4 & 0.4 & 0.3 & 0.1 \\
\hline PW91 & $\mathrm{G}(\mathrm{d})$ & $+\mathrm{G}(\mathrm{d})$ & $++\mathrm{G}(\mathrm{d}, \mathrm{p})$ & $++\mathrm{G}(2 \mathrm{df}, 2 \mathrm{dp})$ & $++\mathrm{G}(3 \mathrm{df}, 3 \mathrm{dp})$ \\
\hline $6-31$ & 0.6 & 0.3 & 0.2 & 0.1 & 0.1 \\
$6-311$ & 0.4 & 0.4 & 0.3 & 0.0 & 0.1 \\
\hline$\omega$ B97X-D & $\mathrm{G}(\mathrm{d})$ & $+\mathrm{G}(\mathrm{d})$ & $++\mathrm{G}(\mathrm{d}, \mathrm{p})$ & $++\mathrm{G}(2 \mathrm{df}, 2 \mathrm{dp})$ & $++\mathrm{G}(3 \mathrm{df}, 3 \mathrm{dp})$ \\
\hline $6-31$ & 0.4 & 0.3 & 0.2 & 0.2 & 0.1 \\
$6-311$ & 0.4 & 0.3 & 0.3 & 0.2 & 0.0 \\
\hline
\end{tabular}


Table 11: Mean Absolute Errors of the DLPNO-CCSD(T)/def2-QZVPP//DFT/basis binding energy $(\mathrm{kcal} / \mathrm{mol})$ for polarization consistent basis sets compared to the DLPNO//DFT/aug-cc-pV5Z level of theory.

\begin{tabular}{lrrrr}
\hline M06-2X & 1 & 2 & 3 & 4 \\
\hline pc & 0.9 & 0.1 & 0.0 & 0.0 \\
aug-pc & 0.7 & 0.2 & & \\
\hline PW91 & 1 & 2 & 3 & 4 \\
\hline pc & 0.4 & 0.1 & 0.0 & 0.0 \\
aug-pc & 0.1 & 0.1 & & \\
\hline$\omega B 97 X-D$ & 1 & 2 & 3 & 4 \\
\hline pc & 0.3 & 0.0 & 0.0 & 0.0 \\
aug-pc & 0.3 & 0.1 & & \\
\hline
\end{tabular}

When using polarization consistent basis sets, M06-2X/pc-1 produces the highest MAE of $0.9 \mathrm{kcal} / \mathrm{mol}$. However, pc-2 with every functional yields similar results to the aug-cc-pV5Z basis set, with MAEs in the range 0.0-0.1 $\mathrm{kcal} / \mathrm{mol}$ (see Table 11).

When using the cc-pVDZ, 6-31G(d), and pc-1 basis sets, reaction R5 yields an error (with respect to the thermal contribution) which over twice the MAE. However, the qualitative results do not change even after removing reaction $\mathrm{R} 5$ from the MAE calculation.

Overall it appears, that to yield a low error in the subsequent calculations of the binding energy, a may-cc-pVDZ, or $6-31++\mathrm{G}(\mathrm{d}, \mathrm{p})$ basis set will be sufficient for optimizing geometries for PW91 and $\omega$ B97X-D. For M06-2X, a slightly larger basis set is required to obtain errors below $0.3 \mathrm{kcal} / \mathrm{mol}$. The slow convergence of the M06-2X functional has been shown in previous studies [69].

\subsubsection{Extension to Larger Clusters}

To investigate if the findings for small clusters are still valid for larger clusters, we have optimized geometries using PW91 functional with $6-31++\mathrm{G}^{* *}$, 6-311++G(3df,3dp), may-cc-pVDZ, may-cc-pVTZ, and aug-cc-pVTZ basis sets and calculated single point energies on top of the DFT geometries using DLPNO. We used $\left(\mathrm{H}_{2} \mathrm{SO}_{4}\right)_{x}\left(\left(\mathrm{CH}_{3}\right)_{2} \mathrm{NH}\right)_{x}$ and $\left(\mathrm{H}_{2} \mathrm{SO}_{4}\right)_{x}\left(\mathrm{NH}_{3}\right)_{x}$ clusters, where $x=2-4$. Figure 7 presents the single point energy differences relative to DLPNO//DFT/aug-cc-pVTZ, and due to computational limitations in case of $4 \mathrm{~A} 4 \mathrm{D}$ relative to DLPNO//DFT/may-cc-pVTZ. May-cc-pVDZ and 


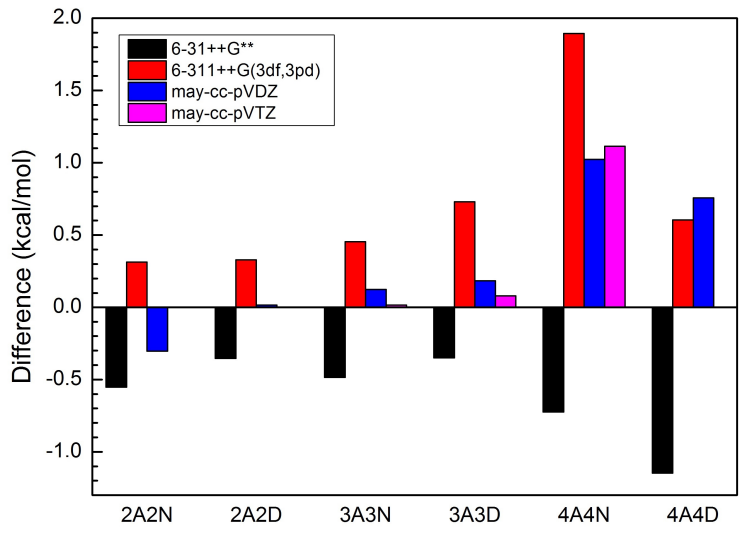

Figure 7: DLPNO-CCSD(T)/def2-QZVPP//PW91/basis single point energy differences between $6-31++\mathrm{G}^{* *}, 6-311++\mathrm{G}(3 \mathrm{df}, 3 \mathrm{dp})$, may-cc-pVDZ, and may-cc-pVTZ relative to aug-cc-pVTZ (and in case of $4 \mathrm{~A} 4 \mathrm{D}$ relative to may-cc-pVTZ). Abbreviations: $\mathrm{A}=\mathrm{H}_{2} \mathrm{SO}_{4}$, $\mathrm{N}=\mathrm{NH}_{3}$, and $\mathrm{D}=\left(\mathrm{CH}_{3}\right)_{2} \mathrm{NH}$.

$6-31++\mathrm{G}^{* *}$ basis sets show good agreement relative to aug-cc-pVTZ, yielding errors in the range $0.02-1.0$ and $0.3-1.1 \mathrm{kcal} / \mathrm{mol}$, respectively. The $6-311++\mathrm{G}(3 \mathrm{df}, 3 \mathrm{dp})$ basis set produces the largest maximum error of 1.9 $\mathrm{kcal} / \mathrm{mol}$ for the $\left(\mathrm{H}_{2} \mathrm{SO}_{4}\right)_{4}\left(\mathrm{NH}_{3}\right)_{4}$ cluster. Generally, the results shows that small basis sets are sufficient for geometry optimizations of atmospheric molecular clusters provided that single point energies are then calculated using higher level methods.

\subsubsection{Implications for Multi-Step Quantum Chemistry}

Composite quantum chemical approaches seeks out to yield a hierarchy of methods (such as $\mathrm{Wn}[70,71,72]$ and $\mathrm{Gn}[73,74,75,76]$ theories), designed to obtain highly accurate thermochemistry. While these methods with high confidence can yield results with sub $\mathrm{kcal} / \mathrm{mol}$ or even sub $\mathrm{kJ} / \mathrm{mol}$ accuracy, they often rely on high level geometries at the $\operatorname{CCSD}(\mathrm{T})$ level with moderate basis sets. For the large systems studied here, this level of theory is certainly out of reach, and DFT is the only method applicable. We are thus unable to assess the absolute error incurred by using DFT instead of e.g. CCSD(T) for the geometry optimizations. For the relative error incurred by optimizing the 
geometries using DFT with a modest basis set (as compared to DFT with a very large basis set), the results in Tables 9-11 are very promising: the errors are amazingly small, and even quite small basis set suffice as long as a few diffuse functions are included. For any reasonable basis set the errors are negligible and errors from post-CCSD $(\mathrm{T})$ terms might actually be a higher

source of errors. This shows great promise for the further development of accurate composite quantum chemical methods based on DFT geometries.

\subsection{Time Consumption}

Besides the accuracy of the calculations, it is also important to look at the computational effort needed. We have calculated the relative computational time and accuracy of $\left(\mathrm{H}_{2} \mathrm{SO}_{4}\right)\left(\mathrm{NH}_{3}\right)$ binding energies for every basis set used in this study. Optimization and frequency calculations have been performed with the PW91 functional. The relative computational time is calculated for the $\left(\mathrm{H}_{2} \mathrm{SO}_{4}\right)\left(\mathrm{NH}_{3}\right)$ cluster using Intel Sandy Bridge E5-2670 hardware on the Taito supercluser of the CSC computing center. We used 2-16 cores depending on the size of the basis set, and we calculated the total computational time by multiplying the number of cores with the wall clock time. Figure 8 presents the accuracy compared to the aug-cc-pV5Z basis set (red bars) and the relative time compared to the smallest $6-31 \mathrm{G}^{*}$ basis set (blue squares).

For double-zeta basis sets, jul-cc-pVDZ gives an energy difference of 0.4 $\mathrm{kcal} / \mathrm{mol}$ with a relative computational time of 4 . Adding more diffuse functions only increases the computational time without any gain in accuracy. In the case of triple-zeta basis sets, it is reasonable to use the may-cc-pVTZ basis set as it needs same relative computational time (10) as cc-pVTZ with a much higher accuracy $(0.3 \mathrm{kcal} / \mathrm{mol})$ as $(2.0 \mathrm{kcal} / \mathrm{mol})$. When adding more diffuse functions, the difference reduces to $0.06 \mathrm{kcal} / \mathrm{mol}$ in case of jun and $0.05 \mathrm{kcal} / \mathrm{mol}$ in case of jul, with relative computational times of 28 and 33, respectively. With cardinal numbers 4,5 , and 6 , jun-cc-pVQZ gives the lowest difference at $0.001 \mathrm{kcal} / \mathrm{mol}$, with a relative computational time of 300 . The aug-cc-pV5Z basis set needs a relative computational time of 5400 and cc-pV6Z needs of 7000. This further confirms that may-cc-pVTZ is suitable for calculating the binding energy of molelcular clusters using DFT. 

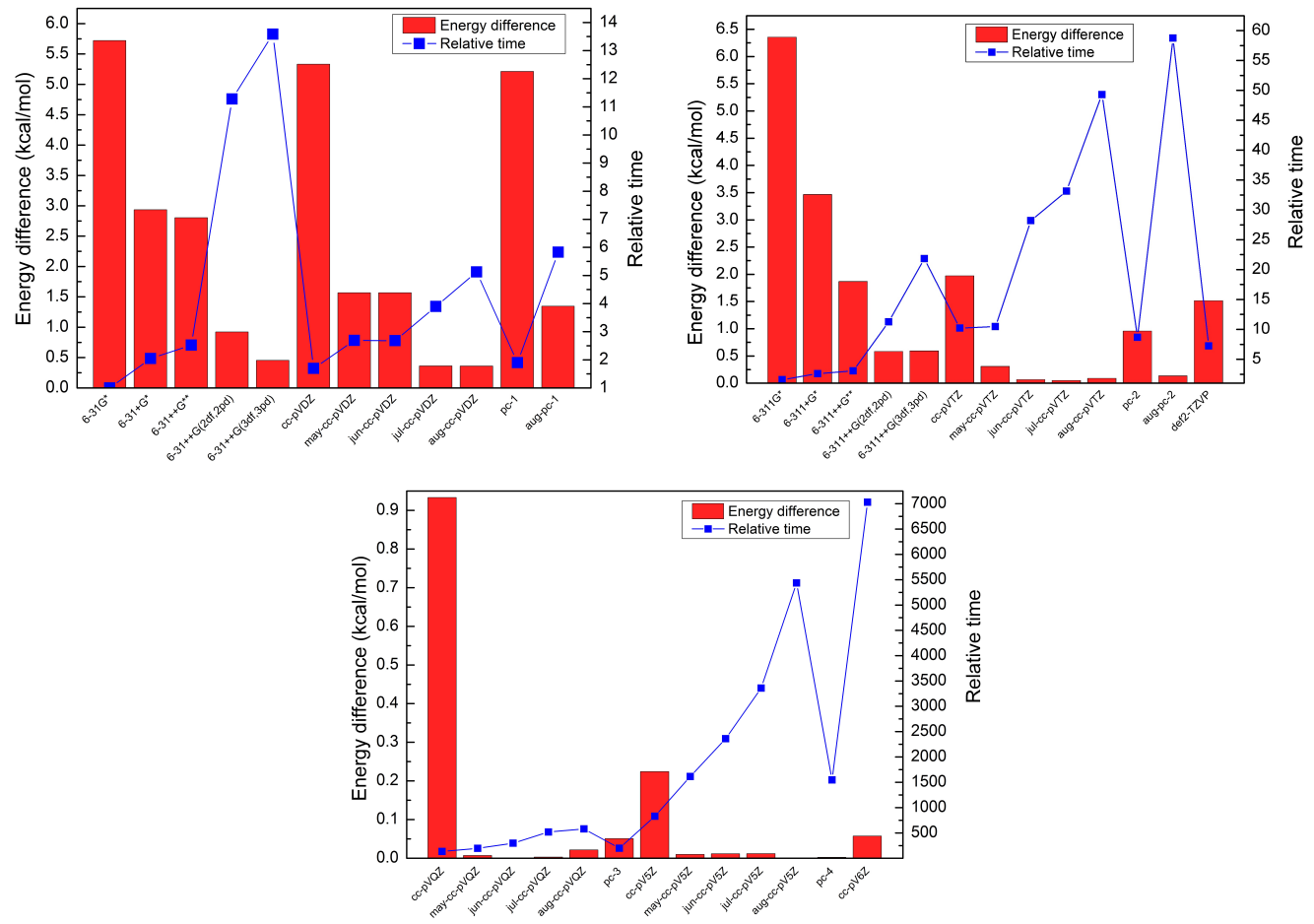

Figure 8: Relative time (blue squares) and accuracy of binding energies (red bars) for the $\left(\mathrm{H}_{2} \mathrm{SO}_{4}\right)\left(\mathrm{NH}_{3}\right)$ cluster calculated using the PW91 functional with double-zeta (top, left), triple-zeta (top, right), and quadruple, quintuple, and sextuple-zeta (down) basis sets. Note the different scale of the axes. 


\section{Conclusions}

We have investigated the basis set convergence of density functionals with respect to the binding energy, thermal contribution to the Gibbs free energy, and the optimized geometry of atmospheric hydrogen-bonded clusters. Including diffuse functions is important for a correct description of loosely bound electrons in practice hydrogen bonds, however, in most cases full augmentation is not needed. Removing the two highest angular momentum diffuse functions from the fully augmented basis set, giving in the may-cc$\mathrm{pV} x \mathrm{Z}$ basis sets, yield as good results as the fully augmented basis sets, at significantly lower computational cost.

For calculating the thermal contribution to the Gibbs free energy of formation, a relatively small basis set may be sufficient. For example may-ccpVDZ and 6-31++G(d,p) give good agreement with aug-cc-pV5Z, with only 3 times higher computational effort than 6-31G*. However, especially M06$2 \mathrm{X}$ requires larger basis set for the geometry optimization for to high-level single point energy corrections to be accurate. $6-31++\mathrm{G}(2 \mathrm{df}, 2 \mathrm{dp})$, may-ccpVTZ, and pc-2 sets yield reliable results with relative computational times of 11, 10, and 9, respectively. For DFT binding energies, the may-cc-pVTZ basis set produces results close to aug-cc-pV5Z, and may-cc-pVQZ has reached the complete basis set limit.

We have studied the effects of anharmonicity and the quasi-harmonic approximation on the thermal contribution to the Gibbs free energy. The anharmonic scaling factors are found to be in the range 0.9405-0.9960, and the effect of actual vibrational anharmonicity at under $100 \mathrm{~cm}^{-1}$ frequencies on the studied molecular clusters is found to been small, with a maximum lowering of $2 \mathrm{kcal} / \mathrm{mol}$ in the thermal contribution to the Gibbs free energy. However, the quasi-harmonic correction for low-lying frequencies is a few percent of the total harmonic thermal contribution, which implies that for large clusters the correction is several kcal/mol. The quasi-harmonic approximation does not affect the computational cost and it is, therefore, possible to apply it to large systems. The study of the accuracy of the quasi-harmonic approximation should be extended to a wider test set because of its importance for large molecular clusters. 


\section{Acknowledgment}

We thank the Academy of Finland and ERC project 57360-MOCAPAF for funding and the CSC-IT Center for Science in Espoo, Finland, for computational resources. J.E. thanks the Carlsberg foundation for financial support.

\section{References}

[1] R. Zhang, A. Khalizov, L. Wang, M. Hu, W. Xu, Nucleation and Growth of Nanoparticles in the Atmosphere, Chem. Rev. 112 (2012) 1957-2011.

[2] J. Elm, N. Myllys, J.-N. Luy, T. Kurtén, H. Vehkamäki, The Effect of Water and Bases on the Clustering of a Cyclohexene Autoxidation Product $\mathrm{C}_{6} \mathrm{H}_{8} \mathrm{O}_{7}$ with Sulfuric Acid, J. Phys. Chem. A 120 (2016) 22402249.

[3] N. T. Tsona, H. Henschel, N. Bork, V. Loukonen, H. Vehkamäki, Structures, Hydration, and Electrical Mobilities of Bisulfate Ion - Sulfuric Acid - Ammonia/Dimethylamine Clusters: A Computational Study, J. Phys. Chem. A 119 (2015) 9670-9679.

[4] J. Elm, C. N. Jen, T. Kurtén, H. Vehkamäki, Strong Hydrogen Bonded Molecular Interactions between Atmospheric Diamines and Sulfuric Acid, J. Phys. Chem. A 120 (2016) 3693-3700.

[5] T. Kurtén, L. Torpo, C.-G. Ding, H. Vehkamäki, M. R. Sundberg, K. Laasonen, M. Kulmala, A density functional study on water-sulfuric acid-ammonia clusters and implications for atmospheric cluster formation, J. Geophys. Res. Atmos. 112 (2007) D04210.

[6] V. Loukonen, T. Kurtén, I. K. Ortega, H. Vehkamäki, A. A. H. Pádua, K. Sellegri, M. Kulmala, Enhancing effect of dimethylamine in sulfuric acid nucleation in the presence of water - a computational study, Atmos. Chem. Phys. 10 (2010) 4961-4974.

[7] T. Olenius, O. Kupiainen-Määttä, I. K. Ortega, T. Kurtén, H. Vehkamäki, Free energy barrier in the growth of sulfuric acid - ammonia and sulfuric acid - dimethylamine clusters, J. Chem. Phys. 139 (2013) 084312. 
[8] S. Schobesberger, H. Junninen, F. Bianchi, G. Lönn, M. Ehn, K. Lehtipalo, J. Dommen, S. Ehrhart, I. K. Ortega, A. Franchin, T. Nieminen, F. Riccobono, M. Hutterli, J. Duplissy, J. Almeida, A. Amorim, M. Breitenlechner, A. J. Downard, E. M. Dunne, R. C. Flagan, M. Kajos, H. Keskinen, J. Kirkby, A. Kupc, A. Krten, T. Kurtén, A. Laaksonen, S. Mathot, A. Onnela, A. P. Praplan, L. Rondo, F. D. Santos, S. Schallhart, R. Schnitzhofer, M. Sipilä, A. Tomé, G. Tsagkogeorgas, H. Vehkamäki, D. Wimmer, U. Baltensperger, K. S. Carslaw, J. Curtius, A. Hansel, T. Petäjä, M. Kulmala, N. M. Donahue, D. R. Worsnop, Molecular understanding of atmospheric particle formation from sulfuric acid and large oxidized organic molecules, Proc. Natl. Acad. Sci. 110 (2013) 17223-17228.

[9] S. Grimme, Accurate description of van der Waals complexes by density functional theory including empirical corrections, J. Comput. Chem. 25 (2004) 1463-1473.

[10] S. Grimme, Semiempirical GGA-type density functional constructed with a long-range dispersion correction, J. Comput. Chem. 27 (2006) $1787-1799$.

[11] S. Grimme, J. Antony, S. Ehrlich, H. Krieg, A consistent and accurate ab initio parametrization of density functional dispersion correction (DFTD) for the 94 elements H-Pu, J. Chem. Phys. 132 (2010) 154104.

[12] J.-D. Chai, M. Head-Gordon, Long-range corrected hybrid density functionals with damped atom-atom dispersion corrections, Phys. Chem. Chem. Phys. 10 (2008) 6615-6620.

[13] L. A. Burns, . V. Mayagoitia, B. G. Sumpter, C. D. Sherrill, Densityfunctional approaches to noncovalent interactions: A comparison of dispersion corrections (DFT-D), exchange-hole dipole moment (XDM) theory, and specialized functionals, J. Chem. Phys. 134 (2011) 084107.

[14] S. Grimme, Density functional theory with London dispersion corrections, Wiley Interdiscip. Rev. Comput. Mol. Sci. 1 (2011) 211-228.

[15] A. Halkier, T. Helgaker, P. Jørgensen, W. Klopper, H. Koch, J. Olsen, A. K. Wilson, Basis-set convergence in correlated calculations on $\mathrm{Ne}$, $\mathrm{N}_{2}$, and $\mathrm{H}_{2} \mathrm{O}$, Chem. Phys. Lett. 286 (1998) $243-252$. 
[16] A. D. Boese, J. M. L. Martin, N. C. Handy, The role of the basis set: Assessing density functional theory, J. Chem. Phys. 119 (2003) 30053014 .

[17] J. Elm, N. Myllys, N. Hyttinen, T. Kurtén, Computational Study of the Clustering of a Cyclohexene Autoxidation Product $\mathrm{C}_{6} \mathrm{H}_{8} \mathrm{O}_{7}$ with Itself and Sulfuric Acid, J. Phys. Chem. A 119 (2015) 8414-8421.

[18] N. Myllys, J. Elm, R. Halonen, T. Kurtén, H. Vehkamäki, Coupled Cluster Evaluation of the Stability of Atmospheric Acid - Base Clusters with up to 10 Molecules, J. Phys. Chem. A 120 (2016) 621-630.

[19] I. K. Ortega, T. Kurtén, H. Vehkamäki, M. Kulmala, The role of ammonia in sulfuric acid ion induced nucleation, Atmos. Chem. Phys. 8 (2008) 2859-2867.

[20] S. Grimme, Supramolecular Binding Thermodynamics by DispersionCorrected Density Functional Theory, Chem. Eur. J. 18 (2012) 99559964.

[21] J. M. Bowman, Self-consistent field energies and wavefunctions for coupled oscillators, J. Chem. Phys. 68 (1978) 608-610.

[22] J. Šebek, L. Pele, E. O. Potma, B. R. Gerber, Raman spectra of long chain hydrocarbons: anharmonic calculations, experiment and implications for imaging of biomembranes, Phys. Chem. Chem. Phys. 13 (2011) 12724-12733.

[23] R. Knaanie, J. Šebek, M. Tsuge, N. Myllys, L. Khriachtchev, M. Räsänen, B. Albee, E. O. Potma, R. B. Gerber, Infrared Spectrum of Toluene: Comparison of Anharmonic Isolated-Molecule Calculations and Experiments in Liquid Phase and in a Ne Matrix, J. Phys. Chem. A 120 (2016) 3380-3389.

[24] L. S. Norris, M. A. Ratner, A. E. Roitberg, R. B. Gerber, Möller-Plesset perturbation theory applied to vibrational problems, J. Chem. Phys. 105 (1996) 11261-11267.

[25] J. O. Jung, R. B. Gerber, Vibrational wave functions and spectroscopy of $\left(\mathrm{H}_{2} \mathrm{O}\right) \mathrm{n}, \mathrm{n}=2,3,4,5$ : Vibrational self-consistent field with correlation corrections, J. Chem. Phys. 105 (1996) 10332-10348. 
[26] A. Willetts, N. C. Handy, W. H. Green, D. Jayatilaka, Anharmonic corrections to vibrational transition intensities, J. Phys. Chem. 94 (1990) $5608-5616$.

[27] B. Temelso, G. C. Shields, The Role of Anharmonicity in HydrogenBonded Systems: The Case of Water Clusters, J. Chem. Theory Comput. 7 (2011) 2804-2817.

[28] B. Temelso, K. A. Archer, G. C. Shields, Benchmark Structures and Binding Energies of Small Water Clusters with Anharmonicity Corrections, J. Phys. Chem. A 115 (43) (2011) 12034-12046.

[29] M. J. Frisch, G. W. Trucks, H. B. Schlegel, G. E. Scuseria, M. A. Robb, J. R. Cheeseman, G. Scalmani, V. Barone, B. Mennucci, G. A. Petersson, H. Nakatsuji, M. Caricato, X. Li, H. P. Hratchian, A. F. Izmaylov, J. Bloino, G. Zheng, J. L. Sonnenberg, M. Hada, M. Ehara, K. Toyota, R. Fukuda, J. Hasegawa, M. Ishida, T. Nakajima, Y. Honda, O. Kitao, H. Nakai, T. Vreven, J. A. Montgomery, Jr., J. E. Peralta, F. Ogliaro, M. Bearpark, J. J. Heyd, E. Brothers, K. N. Kudin, V. N. Staroverov, R. Kobayashi, J. Normand, K. Raghavachari, A. Rendell, J. C. Burant, S. S. Iyengar, J. Tomasi, M. Cossi, N. Rega, J. M. Millam, M. Klene, J. E. Knox, J. B. Cross, V. Bakken, C. Adamo, J. Jaramillo, R. Gomperts, R. E. Stratmann, O. Yazyev, A. J. Austin, R. Cammi, C. Pomelli, J. W. Ochterski, R. L. Martin, K. Morokuma, V. G. Zakrzewski, G. A. Voth, P. Salvador, J. J. Dannenberg, S. Dapprich, A. D. Daniels, Ö. Farkas, J. B. Foresman, J. V. Ortiz, J. Cioslowski, D. J. Fox, Gaussian09 Revision D.01, gaussian Inc. Wallingford CT, 2009.

[30] C. Riplinger, F. Neese, An efficient and near linear scaling pair natural orbital based local coupled cluster method, J. Chem. Phys. 138 (2013) 034106 .

[31] C. Riplinger, B. Sandhoefer, A. Hansen, F. Neese, Natural triple excitations in local coupled cluster calculations with pair natural orbitals, J. Chem. Phys. 139 (2013) 134101.

[32] F. Weigend, R. Ahlrichs, Balanced basis sets of split valence, triple zeta valence and quadruple zeta valence quality for $\mathrm{H}$ to $\mathrm{Rn}$ : Design and assessment of accuracy, Phys. Chem. Chem. Phys. 7 (2005) 3297-3305. 
[33] F. Neese, The ORCA program system, Wiley Interdiscip. Rev. Comput. Mol. Sci. 2 (2012) 73-78.

[34] T. H. Dunning, Gaussian basis sets for use in correlated molecular calculations. I. The atoms boron through neon and hydrogen, J. Chem. Phys. 90 (1989) 1007-1023.

[35] T. H. Dunning, K. A. Peterson, A. K. Wilson, Gaussian basis sets for use in correlated molecular calculations. X. The atoms aluminum through argon revisited, J. Chem. Phys. 114 (2001) 9244-9253.

[36] E. Papajak, D. G. Truhlar, Convergent Partially Augmented Basis Sets for Post-HartreeFock Calculations of Molecular Properties and Reaction Barrier Heights, J. Chem. Theory Comput. 7 (2011) 10-18.

[37] R. A. Kendall, T. H. Dunning, R. J. Harrison, Electron affinities of the firstrow atoms revisited. Systematic basis sets and wave functions, J. Chem. Phys. 96 (1992) 6796-6806.

[38] R. Krishnan, J. S. Binkley, R. Seeger, J. A. Pople, Self-consistent molecular orbital methods. XX. A basis set for correlated wave functions, J. Chem. Phys. 72 (1980) 650-654.

[39] W. J. Hehre, R. Ditchfield, J. A. Pople, Self-Consistent Molecular Orbital Methods. XII. Further Extensions of Gaussian - Type Basis Sets for Use in Molecular Orbital Studies of Organic Molecules, J. Chem. Phys. 56 (1972) 2257-2261.

[40] M. J. Frisch, J. A. Pople, J. S. Binkley, Self-consistent molecular orbital methods 25. Supplementary functions for Gaussian basis sets, J. Chem. Phys. 80 (1984) 3265-3269.

[41] F. Jensen, Polarization consistent basis sets: Principles, J. Chem. Phys. 115 (2001) 9113-9125.

[42] F. Jensen, Erratum: Polarization consistent basis sets: Principles [J. Chem. Phys. 115, 9113 (2001)], J. Chem. Phys. 116 (2002) 3502-3502.

[43] F. Jensen, Polarization consistent basis sets. III. The importance of diffuse functions, J. Chem. Phys. 117 (2002) 9234-9240. 
[44] J. P. Perdew, Y. Wang, Accurate and simple analytic representation of the electron-gas correlation energy, Phys. Rev. B 45 (1992) 13244-13249.

[45] J.-D. Chai, M. Head-Gordon, Long-range corrected hybrid density functionals with damped atom-atom dispersion corrections, Phys. Chem. Chem. Phys. 10 (2008) 6615-6620.

[46] Y. Zhao, D. G. Truhlar, The M06 suite of density functionals for main group thermochemistry, thermochemical kinetics, noncovalent interactions, excited states, and transition elements: two new functionals and systematic testing of four M06-class functionals and 12 other functionals, Theor. Chem. Acc. 120 (2008) 215-241.

[47] R. Peverati, D. G. Truhlar, The quest for a universal density functional: The accuracy of density functionals across a broad spectrum of databases in chemistry and physics, Phil. Trans. R. Soc. A 372 (2014) 20120476.

[48] T. Wu, Y. N. Kalugina, A. J. Thakkar, Choosing a density functional for static molecular polarizabilities, Chem. Phys. Lett. 635 (2015) 257-261.

[49] J. Elm, M. Bilde, K. V. Mikkelsen, Assessment of binding energies of atmospherically relevant clusters, Phys. Chem. Chem. Phys. 15 (2013) 16442-16445.

[50] J. Elm, M. Bilde, K. V. Mikkelsen, Assessment of Density Functional Theory in Predicting Structures and Free Energies of Reaction of Atmospheric Prenucleation Clusters, J. Chem. Theory Comput. 8 (2012) 2071-2077.

[51] H. R. Leverentz, J. I. Siepmann, D. G. Truhlar, V. Loukonen, H. Vehkamäki, Energetics of Atmospherically Implicated Clusters Made of Sulfuric Acid, Ammonia, and Dimethyl Amine, J. Phys. Chem. A 117 (2013) 3819-3825.

[52] E. Papajak, J. Zheng, X. Xu, H. R. Leverentz, D. G. Truhlar, Perspectives on Basis Sets Beautiful: Seasonal Plantings of Diffuse Basis Functions, J. Chem. Theory Comput. 7 (2011) 3027-3034.

[53] J. Elm, K. V. Mikkelsen, Computational approaches for efficiently modelling of small atmospheric clusters, Chem. Phys. Lett. 615 (2014) 26 29 . 
[54] T. Kupka, C. Lim, Polarization-Consistent versus CorrelationConsistent Basis Sets in Predicting Molecular and Spectroscopic Properties, J. Phys. Chem. A 111 (2007) 1927-1932.

[55] H.-X. Zhou, M. K. Gilson, Theory of Free Energy and Entropy in Noncovalent Binding, Chem. Rev. 109 (2009) 4092-4107.

[56] H. S. Muddana, M. K. Gilson, Calculation of Host - Guest Binding Affinities Using a Quantum-Mechanical Energy Model, J. Chem. Theory Comput. 8 (2012) 2023-2033.

[57] R. F. Ribeiro, A. V. Marenich, C. J. Cramer, D. G. Truhlar, Use of Solution-Phase Vibrational Frequencies in Continuum Models for the Free Energy of Solvation, J. Phys. Chem. B 115 (2011) 14556-14562.

[58] R. Sure, J. Antony, S. Grimme, Blind Prediction of Binding Affinities for Charged Supramolecular Host - Guest Systems: Achievements and Shortcomings of DFT-D3, J. Phys. Chem. B 118 (2014) 3431-3440.

[59] Y.-P. Li, J. Gomes, S. M. Sharada, A. T. Bell, M. Head-Gordon, Improved Force-Field Parameters for QM/MM Simulations of the Energies of Adsorption for Molecules in Zeolites and a Free Rotor Correction to the Rigid Rotor Harmonic Oscillator Model for Adsorption Enthalpies, J. Phys. Chem. C 119 (2015) 1840-1850.

[60] I. Funes-Ardois, R. Paton, GoodVibes: GoodVibes v1.0.1, doi: 10.5281/zenodo.60811, 2016.

[61] V. Barone, Anharmonic vibrational properties by a fully automated second-order perturbative approach, J. Chem. Phys. 122 (2005) 014108.

[62] V. Barone, J. Bloino, C. A. Guido, F. Lipparini, A fully automated implementation of VPT2 Infrared intensities, Chem. Phys. Lett. 496 (2010) 157-161.

[63] A. B. Nadykto, J. Herb, F. Yu, Y. Xu, Enhancement in the production of nucleating clusters due to dimethylamine and large uncertainties in the thermochemistry of amine-enhanced nucleation, Chem. Phys. Lett. 609 (2014) 42-49. 
[64] Y. Xu, A. B. Nadykto, F. Yu, J. Herb, W. Wang, Interaction between Common Organic Acids and Trace Nucleation Species in the Earth's Atmosphere, J. Phys. Chem. A 114 (2010) 387-396.

[65] A. B. Nadykto, F. Yu, M. V. Jakovleva, J. Herb, Y. Xu, Amines in the Earth's Atmosphere: A Density Functional Theory Study of the Thermochemistry of Pre-Nucleation Clusters, Entropy 13 (2011) 554569 .

[66] I. K. Ortega, O. Kupiainen, T. Kurtén, T. Olenius, O. Wilkman, M. J. McGrath, V. Loukonen, H. Vehkamäki, From quantum chemical formation free energies to evaporation rates, Atmos. Chem. Phys. 12 (2012) 225-235.

[67] S. F. Boys, F. Bernardi, The calculation of small molecular interactions by the differences of separate total energies. Some procedures with reduced errors, Mol. Phys. 19 (1970) 553-566.

[68] F. B. van Duijneveldt, J. G. C. M. van Duijneveldt-van de Rijdt, J. H. van Lenthe, State of the Art in Counterpoise Theory, Chem. Rev. 94 (1994) 1873-1885.

[69] N. Mardirossian, M. Head-Gordon, Characterizing and Understanding the Remarkably Slow Basis Set Convergence of Several Minnesota Density Functionals for Intermolecular Interaction Energies, J. Chem. Theory Comput. 9 (2013) 4453-4461.

[70] J. M. L. Martin, G. de Oliveira, Towards Standard Methods for Benchmark Quality Ab Initio Thermochemistry - W1 and W2 Theory, J. Chem. Phys. 111 (1999) 1843-1856.

[71] A. D. Boese, M. Oren, O. Atasoylu, J. M. L. M. abd M Kállay, J. Gauss, W3 Theory: Robust Computational Thermochemistry in the $\mathrm{kJ} / \mathrm{mol}$ Accuracy Range, J. Chem. Phys. 120 (2004) 4129-4141.

[72] A. Karton, E. Rabinovich, J. M. L. Martin, B. Ruscic, W4 Theory for Computational Thermochemistry: In Pursuit of Confident Sub-kJ/mol Predictions, J. Chem. Phys. 125 (2006) 144108. 
[73] J. A. Pople, M. Head-Gordon, D. J. Fox, K. Raghavachari, L. A. Curtiss, Gaussian-1 Theory: A General Procedure for Prediction of Molecular Energies, J. Chem. Phys. 90 (1989) 5622-5629.

[74] L. A. Curtiss, K. Raghavachari, G. W. Trucks, J. A. Pople, Gaussian-2 Theory for Molecular Energies of First- and Second-row Compounds, J. Chem. Phys. 94 (1991) 7221-7230.

[75] L. A. Curtiss, K. Raghavachari, P. C. Redfern, V. Rassolov, J. A. Pople, Gaussian-3 (G3) Theory for Molecules Containing First and Second-row Atoms, J. Chem. Phys. 109 (1998) 7764-7776.

[76] L. A. Curtiss, P. C. Redfern, K. Raghavachari, Gaussian-4 Theory, J. Chem. Phys. 126 (2007) 084108. 
Graphical Abstract

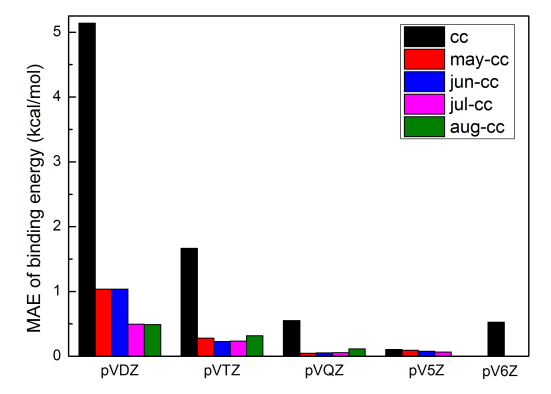

